\title{
A review of studies exploring fetal alcohol spectrum disorders through eye tracking measures
}

Pierre Maurage ${ }^{1, *}, Z^{\prime}$ é Bollen ${ }^{1}$, Nicolas Masson², and Fabien D'Hondt, ${ }^{3,4}$

${ }^{1}$ Louvain for Experimental Psychopathology research group, Psychological Sciences Research Institute, Université Catholique de Louvain, Louvain-la-Neuve, Belgium.

2 Numerical Cognition Group, Psychological Sciences Research Institute and Neuroscience Institute, Université Catholique de Louvain, Louvain-la-Neuve, Belgium.

${ }^{3}$ Univ. Lille, INSERM, U1172, Centre Lille Neuroscience \& Cognition, Lille, France

${ }^{4} \mathrm{CHU}$ Lille, Clinique de Psychiatrie, Unité CURE, Lille, France

${ }^{5}$ Centre National de Ressources et de Résilience Lille-Paris (CN2R), Lille, France

Article Type: Review

Word count: 211 (Abstract); 7234 (Main text)

Number of Tables: 1 Number of Figures: 1 Number of Supplementary Tables: 1

E-mail addresses: pierre.maurage@uclouvain.be (P. Maurage);

zoe.bollen@uclouvain.be (Z. Bollen); nicolas.masson@uclouvain.be (N. Masson);

fabien.d-hondt@univ-lille.fr (F. D'Hondt)

*All correspondence should be sent to:

Pierre Maurage, Université catholique de Louvain, Faculté de Psychologie

Place du Cardinal Mercier, 10, B-1348 Louvain-la-Neuve, Belgium

Tel: +32 10 479245. Fax:+32 10 473774. E-mail: pierre.maurage@uclouvain.be 


\section{Abstract}

The widespread cognitive and cerebral consequences of prenatal alcohol exposure have been established during the last decades, through the exploration of fetal alcohol spectrum disorders (FASD) using neuropsychological and neuroscience tools. This research field has recently benefited from the emergence of innovative measures, among which eye tracking, allowing a precise measure of the eye movements indexing a large range of cognitive functions. We propose a comprehensive review, based on PRISMA guidelines, of the eye tracking studies performed in populations with FASD. Studies were selected from the PsycINFO, PubMed and Scopus databases, and were evaluated through a standardized methodological quality assessment. Studies were classified according to the eye tracking indexes recorded (saccade characteristics, initial fixation, number of fixations, dwell time, gaze pattern) and the process measured (perception, memory, executive functions). Eye tracking data showed that FASD are mostly associated with impaired ocular perceptive/motor abilities (i.e., altered eye movements, centrally for saccade initiation), lower accuracy as well as increased error rates in saccadic eye movements involving working memory abilities, and reduced inhibitory control on saccades. After identifying the main limitations presented by the reviewed studies, we propose guidelines for future research, underlining the need to increase the standardization of diagnosis and evaluation tools, and to improve the methodological quality of eye tracking measures.

\section{Keywords}

Eye movements; alcohol; fetal alcohol syndrome; alcohol-related neurodevelopmental disorder; prenatal alcohol exposure 


\section{Introduction}

Alcohol-related disorders encompass various conditions, all being related to physical and mental health damages (WHO, 2018). Beyond the (neuro-)psychological and brain impairments occurring during acute alcohol consumption (Bjork and Gilman, 2014; Field et al., 2010) and those related to chronic excessive alcohol consumption among individuals diagnosed with severe alcohol-use disorder (gathering former categories of alcohol abuse and alcohol dependence, Bühler and Mann, 2011; Stavro et al., 2013), the fifth edition of the Diagnostic and Statistical Manual of Mental Disorders [DSM-5, American Psychiatric Association (2013)] includes the diagnosis of neurodevelopmental disorder associated with prenatal alcohol exposure. Such in utero exposure to alcohol has negative consequences for a large range of physiological systems, involving sensorial (Ribeiro et al., 2007), musculoskeletal (Myrie and Pinder, 2018), cardiac (Yang et al., 2015) or gastro-intestinal (Hofer and Burd, 2009) abnormalities, but is centrally harmful for the cerebral development of the fetus. This leads to the emergence of cognitive problems, as well as serious behavioral and social maladjustment (Day et al., 2013; Kodituwakku, 2009; Rasmussen, 2005). The umbrella term of "fetal alcohol spectrum disorder" (FASD) is commonly used to describe several subtypes of adverse effects caused by prenatal alcohol exposure. These subtypes include alcohol-related neurodevelopmental disorder (ARND, characterized by cognitive and neurobehavioral impairments, Chudley et al., 2005), as well as partial fetal alcohol syndrome (pFAS) and fetal alcohol syndrome (FAS), which are moreover characterized by central nervous system dysfunctions, facial dysmorphology, and growth deficits (these alterations being more intense and consistent in FAS than in pFAS). These subtypes of FASD are thus all characterized by a pervasive pattern of cognitive and/or cerebral deficits, which have been extensively documented during the last decades through the use of 
neuropsychological and neuroscience tools. The global description of impaired language skills (McGee et al., 2009) or reduced intellectual quotient (Vaurio et al., 2011) has been refined by more specific explorations now offering a comprehensive view of the largescale impairments presented by this population: FASD is associated with reduced performances in motor abilities (Doney et al., 2014), attention (Bertrand et al., 2005), short-term (Aragón et al., 2008) and long-term (Crocker et al., 2011) memory, and executive functions (Khoury et al., 2015). These impairments are underpinned by structural and functional brain modifications which encompass subcortical and cortical regions (Diwadkar et al., 2013; Gautam et al., 2015; Moore et al., 2014).

Interestingly, various neuroscience techniques [e.g. magnetoencephalography (MEG) Bolaños et al., 2017; electrophysiology, Gerhold et al., 2017] have been recently used to increase the theoretical and experimental knowledge regarding the behavioral and brain correlates of FASD. Among these innovative tools, eye tracking measures appear as a very promising technique, notably to offer a better understanding of the links between cognitive and cerebral impairments. Indeed, by allowing the precise detection of eye position and gaze direction with a high temporal resolution, eye tracking indexes bring new insights regarding the underlying brain mechanisms involved in a large variety of cognitive tasks (Luna et al., 2008). The blooming research field of eye tracking in healthy and pathological populations has developed a large range of experimental paradigms linking eye-related measures (including ocular pursuit, saccadic movements, gaze scanpaths or pupillary diameter, Leigh and Kennard, 2004; Lisberger, 2010) with cognitive or brain functions (Eckstein et al., 2017; Popa et al., 2015). Beyond their general usefulness to renew the understanding of neurocognitive abilities in healthy and pathological samples, eye tracking measures appear particularly adapted to deepen the results obtained in FASD through behavioral and neuroscience techniques. Indeed, on the one hand, the various physiological eye movements measured by means of eye 
tracking are under the control of specific neural networks responsible of programming motor schemes to orient (i.e., saccades) or to maintain (e.g., fixation, smooth pursuit) the gaze towards a certain portion of space (see Baird-Gunning and Lueck, 2018; Shaikh and Zee, 2018 for recent reviews). For instance, it is known that frontal and parietal regions are part of a network controlling saccades (e.g., Coe and Munoz, 2017; Wardak et al., 2011), and that the control of saccade accuracy is undertaken by the cerebellum (e.g., Beh et al., 2017; Kunimatsu et al., 2016). On the other hand, recent studies have identified the main brain areas impacted in FASD. Most of them highlighted that the volume and structure of the brain, especially in the corpus callosum, cerebellum, and parietal regions, is damaged. They also acknowledged some functional and neurochemical differences in various brain regions (see Donald et al., 2015; Lebel et al., 2011; Norman et al., 2009 for reviews). Because of the striking overlap between the regions damaged in FASD and the ones involved in eye movements, analyzing gaze patterns appears as an optimal method for understanding how these structural damages cause functional impairments in FASD. Using eye tracking measures to observe abnormal gaze patterns in FASD participants could thus inform on the integrity of the underlying brain structures.

Several studies have already applied eye tracking measures to populations presenting FASD, but no review has been proposed on this topic, which hampers to obtain a comprehensive overview of this emerging research field. Therefore, our objective is to propose a review of all the studies which used valid eye tracking measures among populations presenting FASD. This global research question was specified through the PICOS procedure (Population, Intervention, Comparator, Outcome, Setting; Liberati et al., 2009). Regarding Population, we considered studies which included human participants presenting prenatal alcohol exposure. We considered the whole spectrum of fetal alcohol disorders, including FAS, pFAS or ARND. Concerning Intervention, we included studies proposing a reliable clinical diagnosis or valid measure of prenatal 
alcohol exposure. Regarding Comparator, studies were considered if they offered a reliable comparison between the experimental group (confronted with prenatal alcohol exposure) and a matched control group. The Outcome was focused on studies which proposed at least one reliable eye tracking measure (i.e., initial fixation, number/time of saccades, eye movements, gaze direction, dwell time, pupillary measure) as a main dependent variable. Finally, regarding the Setting, we included studies related to any type of design based on comparisons between groups or experimental conditions (i.e., interventional, observational, cross-sectional). Single-case or case series studies were excluded, as well as papers not reporting experimental data (i.e., reviews, meta-analyses, replies, commentaries, errata).

\section{Methods}

\subsection{Articles identification and selection procedure}

For this review, we followed the guidelines of the Preferred Reporting Items for Systematic reviews and Meta-Analyses (PRISMA) and adhered to their 27-item checklist (Moher et al., 2009). Three databases were consulted (PsycINFO, Pubmed and Scopus). We focused on articles published, between the $1^{\text {st }}$ of January 2000 and $15^{\text {th }}$ of August 2019, which were in English and peer-reviewed. The search phrase combined eye tracking (i.e., "eye tracking" OR "eye-tracking" OR "eye movements" OR "visual tracking" OR "gaze tracking") and fetal alcohol (i.e., "fetal alcohol syndrome" OR "fetal alcohol disorder" OR "fetal alcohol spectrum") terms. The initial search led to identifying 225 papers (11 in PsycINFO, 11 in Pubmed, 203 in Scopus). The papers to be included in the review were then selected according to a 3-step procedure (Figure 1): First, 204 unique papers were identified through duplicates removal. Second, title and abstracts were individually screened, and papers which did not include human participants (i.e., animal 
study, $\mathrm{N}=32)$ or experimental data $(\mathrm{N}=58)$ were excluded. This step thus led to the exclusion of 90 papers. Third, the 114 remaining papers were screened through full-text reading, leading to the exclusion of 99 papers, which did not present any valid eye tracking measure $(\mathrm{N}=41)$ or did not offer a diagnosis or reliable evaluation of fetal alcohol spectrum disorders $(\mathrm{N}=58)$. This procedure ended up in the inclusion of 15 papers in the review process. For the sake of clarity and despite some overlap across processes in several studies, we have decided to organize sections in subparts, each focusing on one type of cognitive process, and we will thus successively present the work focusing on perceptive processes, memory and higher cognitive abilities (executive functions and decision making). We will finally present two studies that aimed at using eye tracking measures to improve the detection and diagnosis of FASD. It should be noted that, as the present review is focused on eye tracking measures in FASD, the results section will primarily consider, for each study, the data directly related to eye movements and eye tracking indexes. While other measures complementing eye tracking ones (and centrally those related to brain structure or functioning, obtained through neurophysiological or neuroimaging techniques) will also be mentioned, the quality assessment will be limited to eye tracking measures, and the main outcomes will only be comprehensively described for those measures.

\subsection{Methodological quality assessment}

The methodological quality of each study was assessed using an adapted version of the "quality assessment tool for observational cohort and cross-sectional studies", developed by the National Heart, Lung and Blood Institute (NHLBI, 2014). This 11-item scale, widely used in various research fields and notably in recent review papers on alcohol-related disorders (e.g., Carbia et al., 2018; Maurage et al., 2020), indeed appears as the most appropriate for the type of studies considered in the present paper (as all are cross- 
sectional studies). As four items of the original scale were not pertinent here (i.e., item 3: "Was the participation rate of eligible persons at least 50\%?"; item $4 a$ : "Were all the subjects selected or recruited from the same or similar populations (including the same time period)?"; item 10: "Was the exposure(s) assessed more than once over time?"; item 13: "Was loss to follow-up after baseline $20 \%$ or less?"), these items have been removed from the evaluation. Moreover, as several key items related to statistical analyses (item 5), exposure measures (item 9), outcome measures (item 11) and confounding variables (item 14) included several sub-questions, they have been split into separated items. The final methodological assessment scale used here comprised 17 items with a binary answer (Yes/No), leading to a maximum score of 17. For each study, a percentage score (i.e., number of items with a "Yes" answer divided by 17) was computed. Supplementary Table 1 presents the detailed score obtained for each study on each item.

\subsection{Data extraction and synthesis}

A systematic data extraction procedure was used to individually determine the main characteristics of each paper, regarding five categories of variables (adapted from the PICOS procedure): (1) Participants (sample size, age, gender ratio, exclusion criteria); (2) Exposures (psychiatric/neurological diagnosis or (sub-)clinical classification, alcoholconsumption measure, psychopathological comorbidities); (3) Comparator (control group presence and size, matching variables); (4) Experimental design (processes measured, tasks, stimuli, eye tracking indexes, eye tracking materials); (5) Outcomes (main results, limitations, key conclusions related to eye tracking measures). A comprehensive synthesis of the data extracted from each study is presented in Table 1. 


\section{Results}

\subsection{Quality assessment}

As described in Supplementary Table 1, the studies included in this review presented several crucial strengths: most of them clearly stated the research questions and objectives, presented a quite large sample size (higher than 60 in seven studies), offered a clear definition and measure of FASD (through established diagnostic criteria), and centrally used sound experimental protocols, leading to reliable eye tracking measures. Moreover, all studies used validated eye tracking materials with sufficient sample rate $(\geq 240 \mathrm{~Hz})$ : Most studies (11/15) used a head-free infrared camera (EyeLink 1000, 500$1000 \mathrm{~Hz})$, while the remaining ones respectively used electrooculogram $(1000 \mathrm{~Hz}$, Green et al., 2007), or head-mounted displays (EyeLink II, 500Hz, Tseng et al., 2013; ISCAN eye tracker, $240 \mathrm{~Hz}$, Green et al., 2009; 2013). It should nevertheless be underlined that most studies did not propose a justification of the sample size used or a statistical power estimation, and most of them regrouped different FASD subtypes, hampering a clear exploration of the variation of eye tracking measures deficits according to FASD subtype. Moreover, most studies did not take into account key potential biasing variables [e.g., parental alcohol consumption, participants' alcohol consumption (as several studies included adolescents)].

\subsection{Main outcomes}

Fifteen studies used eye tracking measures in FASD (Table 1). Thirteen studies used eye tracking measures to determine the impairments related to perceptive, memory or executive abilities in children or adolescents presenting impairments due to prenatal alcohol exposure, and two studies used such measures to develop screening tools improving the early detection of such exposure. The developmental consequences of 
prenatal alcohol exposure are grouped under the FASD label but can be divided into several subtypes (namely FAS, pFAS, or ARND), which will be mentioned and compared in this review.

\section{Perceptive abilities}

The first study using eye tracking in children with FASD, conducted by Green et al. (2007), aimed at offering initial insights on eye movements deficits (saccadic velocity and inhibition) in this population. They used the saccade paradigm, in which participants first have to watch a fixation point, and then to perform a saccade towards (prosaccade condition) or away from (antisaccade condition) a peripheral target appearing on one side of the screen. The eye tracking indexes showed that FASD is characterized by (1) increased saccadic reaction times (i.e., the delay between the appearance of a stimulus in the peripheral visual field and the first eye movement towards this stimulus); (2) increased direction errors (i.e., the percentage of saccades performed in the wrong direction, according to the instructions) in the prosaccade task, and (3) reduced express saccades (i.e., the saccades performed with a very short latency, between 90 and 140ms after the appearance of the peripheral stimulus). Despite the very low sample size, FASD thus appears associated with impairments in early perceptive abilities involved in eye movements (i.e., saccadic velocity), but also in the control of these movements, as the high proportion of direction errors stresses a deficit for the inhibitory control of saccades. This result thus already suggests the presence of executive deficits related to eye movements in this population. However, as group differences regarding direction errors were only found in the prosaccade task, where inhibitory abilities are not involved, these conclusions regarding high-level processing appeared premature and had to be extended. Capitalizing on these preliminary data, Green et al. (2009) also used the saccade task among children or adolescents presenting various FASD subtypes and 
comorbidities in order to further characterize their oculomotor impairments. Results mainly confirmed that children with FASD globally presented longer saccadic reaction times (i.e., the time between target appearance and initiation of the first saccade), independently of the experimental condition, and increased error rates. This general effect however varied according to: (1) the subtype of FASD, as children with FAS presented slower saccades in prosaccade and antisaccade conditions, while children with pFAS were only impaired for antisaccade condition, and children with ARND for prosaccade condition; (2) the age, as the deficit was present for all age groups, but stronger in younger children. This study, in line with the previous one (Green et al., 2007), thus suggests that children with FASD are impaired for the automatic (i.e., initiating a saccade in the prosaccade condition) processes related to eye movements, but also for their inhibitory control, as they identified difficulties to avoid a saccade in the antisaccade condition, opening the way for an exploration of executive processes related to eye movements (see the section dedicated to executive functions).

Two studies proposed to deepen the exploration of the perceptive deficits related to eye movements in FASD. In the first one, Paolozza et al. (2015) focused on prosaccade results to determine the differential eye movements deficit across genders. Beyond the replication of reduced saccade speed in FASD, they demonstrated a different pattern of deficits between males and females: While males mostly presented reduced saccadic precision (i.e., endpoint error), females' saccades were characterized by reduced velocity, which suggests a gender-dependent impact of alcohol neurotoxicity on eye movements. The second one (Paolozza et al., 2016) had the main objective to explore immediate neural plasticity by means of a saccadic carry-over effect (operationalized as the influence of previous target's location on the saccade performed in the next trial) measure. It has indeed been suggested that this short-term saccadic adaptation following the movement of a previous target could represent immediate neural plasticity (Dorris et 
al., 2000). The prosaccade task was used, and the influence of the first (N-1) and second $(\mathrm{N}-2)$ previous trials on each trial's saccadic reaction time were computed. Results showed a group-independent effect of the previous trial (i.e., faster saccadic reaction times and shorter saccades when the target was presented in the opposite side than in the previous trial), suggesting that children with FASD have a preserved rapid neural plasticity in the sensory system of the eye movement circuitry.

The cerebral correlates of these perceptive deficits reported at the behavioral level have been more directly explored in three studies using neuroimaging techniques. First, Green et al. (2013) used diffusion tensor imaging to determine the structural brain correlates of oculomotor deficits in FASD. While the results obtained in participants with FASD for saccadic reaction times and direction errors were in line with those reported earlier (Green et al., 2007; 2009), the absence of control group in this study hampers to draw any conclusion regarding the presence of genuine eye movements impairments in this sample. However, intra-group correlations showed that saccadic reaction times in the antisaccade task were positively related to fractional anisotropy in the anterior/posterior corpus callosum. Fractional anisotropy is frequently considered as an index of white matter integrity (higher fractional anisotropy being commonly interpreted as indicating higher myelination, fiber density and/or axonal diameter) but, as underlined by the authors, this factor cannot be univocally interpreted as reflecting higher white matter organization, as it can be influenced by confounding factors (Jones et al., 2013), and these results should thus be interpreted with caution. Results also showed that saccadic reaction times in the prosaccade task were positively correlated with fractional anisotropy in the genu of the corpus callosum, and negatively correlated with fractional anisotropy in the left cerebellum. This last correlation is coherent, suggesting that reduced structural integrity of the cerebellum might underlie the low-level eye movements impairments observed in FASD. Conversely, the positive correlation found between saccadic reaction 
times and functional anisotropy in the corpus callosum suggests that a better white matter organization (as suggested by higher fractional anisotropy) in this region would be related to increased eye movements deficits in FASD, which is at odds with the available literature (despite the fact that the authors conclude that this correlation also suggests that the corpus callosum is involved in oculomotor deficits).

Coffman et al. (2013) also focused on the exploration of the early brain correlates of visual processing in the occipital cortex, and particularly on the latency of primary visual responses. They used MEG during a prosaccade task in adolescents with FASD. The task was only focusing on low-level perceptive abilities, as participants had first to focus their gaze on a cross in the middle of the screen, and then to perform a saccade towards a white circle presented in the left or right peripheral visual field, while basic eye tracking measures (i.e., saccadic reaction times) were recorded. Brain imaging results mostly showed that FASD is associated with delayed latency of the early cerebral processing of visual stimulations, particularly for stimuli presented in the peripheral visual field. In other words, FASD is related to slower processing in the primary visual cortex, which offers the cerebral correlates of the saccadic reaction times delay reported earlier (Green et al., 2007). Eye tracking measures were mostly used as a control (to check that participants were correctly focusing their gaze on the fixation cross, and then performing saccadic movements towards the target), but saccadic reaction times led to results in contradiction with those obtained through MEG: despite a significant correlation between eye tracking and cerebral measures, no delayed saccadic reaction times were found in participants with FASD compared to controls (which might be related to a lack of statistical power, or to the merging of participants presenting various FASD subtypes). Despite this incoherence between behavioral and brain indexes, the authors conclude that basic visual impairments might partly explain the higher-level deficits in this population, by contributing to the deficits observed for memory and executive functions, as described in 
the following sections. A complementary study (Stephen et al., 2013) from the same research group also used MEG in an identical prosaccade paradigm, to determine the modifications of gamma oscillations in FASD. Eye tracking results were very close to those presented by Coffman et al. (2013), as this study consisted in a deepening of the MEG analyses performed on a nearly identical dataset: adolescent participants with FASD did not show any eye movements' deficit, neither for saccadic reaction times nor for saccade amplitude or peak velocity. MEG results showed that the delayed early visual processing in FASD reported by Coffman et al. (2013) was related to increased gammaband power in the right central cortex. While no correlation was found between eye tracking and cerebral measures, this result might suggest that the neural activity underlying the saccade network is globally modified in FASD, beyond the reduced activity in the primary visual cortex.

\section{Memory}

Paolozza et al. (2013) measured saccadic efficiency in children with FASD ( $N=27)$ compared to matched controls, in order to test the functioning of the cortical and subcortical networks involved in the accuracy and control of eye movements. In line with previous studies (Green et al., 2009), they used prosaccade and antisaccade tasks, but they added a memory-guided task: participants had to hold their gaze on the central fixation point while two peripheral targets were presented successively and then, after the disappearing of these targets, to perform two saccades towards the successive locations of the targets. While children with FASD did not present saccadic impairment in the prosaccade condition, they showed a higher rate of corrective saccades (i.e., they more often needed several saccades to attain the target), had lower saccadic precision, and displayed lower saccadic accuracy (as well as increased error rates) in the antisaccade condition. Centrally, their accuracy was globally reduced compared to controls in the 
memory-guided condition. This study thus confirmed earlier results (Green et al., 2009, while no deficit was observed here for saccadic reaction times), suggesting that FASD is associated with lower saccadic accuracy, particularly when memory processes are requested to efficiently perform the task. The authors suggested, in line with earlier results (Green et al., 2013), that this deficit might be related to cerebellum dysfunction, but the absence of brain functioning measures, as well as the fact that the deficit is mostly present under high cognitive load (underlain by cortical rather than cerebellar activations), should lead to be cautious when inferring the potential cerebral areas involved. Another study (Paolozza et al., 2014a) aimed at directly addressing, among children with FASD, the role played by memory in eye movements disorders. They followed the same logic by proposing a simultaneous measure of eye movements, memory, and visuospatial impairments. Children with FASD were unsurprisingly impaired in working memory (e.g., digit recall task) and visuospatial (line orientation task) abilities, as well as in eye movements measures (i.e., reduced performance in prosaccade, antisaccade and memory-guided tasks, together with lower saccadic accuracy in prosaccade and antisaccade tasks). Significant correlations were found between the two categories of deficits: memory-guided impairment was significantly correlated with reduced working memory performance, and prosaccade accuracy deficits with reduced visuospatial results. This study emphasized the links between eye movements and memory functions deficits, but its correlational approach did not allow to prove that these two categories of deficit share similar underlying processes. Finally, Hemington and Reynolds (2014) used electrophysiological measures to determine the cerebral correlates of this working memory deficit in FASD. They also used a memory-guided task, but with different levels of working memory load, as participants had to perform successive saccades towards the positions previously occupied by one, two or three stimuli. As expected, FASD was associated with reduced eye movements performance, specifically when multiple 
locations had to be encoded in working memory (i.e., two and three stimuli, while no deficit was observed in the condition including only one stimulus). As eye tracking measures were only used to detect premature saccades and to determine successive gaze locations (no saccadic reaction time, velocity, amplitude measures were analyzed), this deficit mostly indexes working memory impairment in FASD (i.e., remembering the locations occupied by the stimulus), rather than a specific deficit for eye movements. Moreover, the use of a unique electrode recording brain activity strongly limits the insights offered by this study regarding the brain correlates of eye movements deficits, but the behavioral impairment was related to globally reduced power in the alpha and theta bands.

\section{Executive functions}

Impairments regarding the executive control of saccades in FASD (i.e., increased difficulty to refrain a saccade in the antisaccade condition) had already been evoked by aforementioned studies exploring perceptive abilities (Green et al., 2007; 2009), but they have been the main focus of three studies. The first one (Paolozza et al., 2014b) aimed at determining the correlations between eye movements and executive deficits in this population through antisaccade and memory-guided saccade tasks, and while also administering a comprehensive cognitive battery. They showed that children with FASD (and to lesser extent children with prenatal alcohol exposure who did not meet FASD diagnosis criteria) simultaneously presented a reduced performance in cognitive functions (auditory sustained and divided attention, switching, inhibition) and altered eye movements (increased error rates in antisaccade and memory-guided tasks). Centrally, a significant correlation was found, specifically in the FASD group, between antisaccade and inhibition/switching deficits, suggesting that these abilities might be underpinned by identical brain regions. However, eye tracking results were not reported, and the fact that the main result was only based on a correlation hampers to draw any causal link between 
eye movements and executive dysfunctions. Moreover, such behavioral studies cannot help to determine the brain correlates of eye movements, which have been the central focus of more recent works by this group, exploring white matter integrity and connectivity in FASD. In the study by Paolozza and colleagues (2014c), eye tracking measures (saccadic performance in antisaccade and memory-guided tasks) were used as a proxy for response inhibition, and the authors centrally aimed at exploring the links between these eye tracking measures and corpus callosum integrity. In coherence with previously reported results, children with FASD displayed slower saccadic reaction times and more saccadic direction/anticipatory errors in the antisaccade task, as well as more saccadic sequence/timing errors in the memory-guided task. Nevertheless, the only group difference regarding corpus callosum integrity was a higher mean diffusivity in the splenium among children with FASD (interpreted as an index of alcohol neurotoxicity). As fractional anisotropy in the splenium was positively correlated with inhibition performance in the control group, the authors suggested that the white matter abnormalities observed in the splenium in FASD might lead to response inhibition deficits. However, this correlation was not found in FASD. Another paper (Paolozza et al., 2017) presented the same goal (i.e., determining the links between white matter integrity and eye tracking measures), but with an extension of diffusion-tensor imaging measures. Beyond corpus callosum, the authors measured the integrity of 15 white matter tracts, and combined it with eye movements (prosaccade) and cognitive measures (executive functions and working memory). Children with prenatal alcohol exposure (this group mixing FASD children with children without a formal FASD diagnosis) presented significantly reduced fractional anisotropy in seven white matter regions (including corpus callosum subregions and cingulum) compared to controls. Here again, while positive correlations were found among control participants between fractional anisotropy and cognitive performance, such correlation was not found in children with prenatal alcohol exposure. 
This contradicts the results observed by Green et al. (2013), reporting correlations between saccadic reaction times and fractional anisotropy (i.e., positive correlation with corpus callosum, and negative with the cerebellum) in FASD.

\section{Diagnosis/Screening tools}

Two studies went beyond the identification of FASD-related deficits presented in the previous studies, which were based on the comparison between participants with FASD and healthy controls. These two studies indeed proposed to improve the detection or diagnosis of FASD through the development of screening tools based on eye tracking indexes. First, Tseng et al. (2013) used a more ecological evaluation of eye movements by performing eye tracking measures while participants were watching short highdefinition video clips (specifically chosen for their visual salience), and by capitalizing on machine learning methods to differentiate patients from control participants based on these measures. Through a combination of oculomotor (saccade amplitude, fixation durations), saliency (links between expected and real gaze orientation) and group (variations in gaze allocation) features recorded in each participant (including 13 children with FASD and 24 controls), a classifier based on feature selection allowed to efficiently distinguish children with FASD from controls with a 79.2\% accuracy, and from children with attention deficit hyperactivity disorder with a 90.4\% accuracy. The main characteristic of children with FASD was an atypical bottom-up (saliency-based) and top-down (related to attentional control) pattern of eye movements, leading to the conclusion that eye tracking measures might constitute an efficient classification tool to complement cognitive evaluation and psychiatric diagnosis in children. However, the limited sample size, the absence of distinction between FASD sub-diagnoses in the analyses, and the limited control of biasing factors (e.g., medication, comorbidities) raise doubts about the current validity of this method. More recently, Zhang et al. (2019) developed a multimodal 
screening protocol whose aim was to improve the early detection of FASD in children and adolescents, using machine learning methods. The full protocol included diffusion tensor imaging, psychometric tests (i.e., developmental neuropsychological assessment) and scanpaths measures during free video watching, but also three eye tracking tasks repeatedly used in the above-mentioned studies, namely prosaccade, antisaccade, and memory-guided (with two-targets) tasks. Eighteen, 15 and 26 eye movements indexes were included in the classification analyses for the prosaccade, antisaccade, and memory-guided tasks, respectively. These indexes encompassed saccadic reaction time, velocity, amplitude, acceleration and duration, but also the percentage of express saccades, as well as direction and anticipatory errors. Classification accuracy (i.e., the correct distinction between FASD and healthy control participants) was first evaluated on each assessment separately, showing a better accuracy for antisaccade $(76.09 \%)$ than for prosaccade (69.57\%) and memory-guided (65.22\%) tasks, the most useful indexes being related to saccadic accuracy. Then, a multimodal approach for classification accuracy evaluation was performed, showing that the best distinctive accuracy (84.78\%) was obtained when combining prosaccade/antisaccade tasks, video watching scanpaths and psychometric tests. The combination of antisaccade indexes and psychometric tests also reached excellent accuracy (82.61\%). Based on these results, the authors proposed a clinical protocol based on a two-step screening, starting with the prosaccade task and video watching scanpaths (Step 1), and then completed (particularly for adolescents) by the antisaccade task and/or neuropsychological tests (Step 2). Applying such screening in therapeutic settings might offer a reliable estimation of the presence and extent of FASD in children and adolescents, at a quite limited cost.

\section{Discussion}


The main insight offered by this first review encompassing all eye tracking explorations in FASD is to clearly underline that all these studies, through the use of various experimental paradigms and of a large range of eye movements indexes, significantly extended previous neuropsychological and neuroscience results, by showing that FASD is associated with abnormalities in the cognitive processes underlying eye movements. Most studies focused on the measure of low-level, perceptive-motor abilities through tasks requesting to perform saccades towards a peripheral stimulus. These data revealed that, while the immediate neural plasticity of the visual system appears preserved in FASD (Paolozza et al., 2016), this population presents impaired eye movements, centrally for saccade initiation (Green et al., 2009), as indexed by increased saccadic reaction times (Green et al., 2007). This impairment is correlated with alterations in cerebellar white matter fibers (Green et al., 2013). A gender effect is also observed, as a reduced saccadic speed/precision is reported in males while a reduced saccadic amplitude is found in females (Paolozza et al., 2015). It should, however, be noted that two neuroscience studies (Coffman et al., 2013; Stephen et al., 2013), while respectively reporting delayed primary visual cortex response and modified magnetoencephalographic activity in the brain network generating saccades among individuals with FASD, did not report any eye movements deficit at the behavioral level. Regarding higher-level cognitive abilities, it was first shown that, during memory tasks, FASD is related to a higher variability, lower accuracy and increased error rates in saccadic eye movements (Paolozza et al., 2013), which are correlated with working memory impairments (Paolozza et al., 2014a) and associated with reduced alpha and theta electrophysiological activity (Hemington and Reynolds, 2014). Second, concerning executive functions, FASD is associated with increased saccadic errors (Paolozza et al., 2014b) and slower saccades (Paolozza et al., 2014c) during the antisaccade task, these deficits being correlated with more global executive impairments and potentially 
underpinned by splenium (Paolozza et al., 2014c) and white matter (Paolozza et al., 2017) abnormalities. Finally, studies trying to develop screening tools to improve the early identification or diagnosis of FASD showed that the impaired eye tracking pattern can be identified through a machine learning-based classifier (Tseng et al., 2013), and that a screening procedure including the measure of saccades towards and away from a peripheral stimulus can efficiently distinguish healthy controls from individuals presenting FASD (Zhang et al., 2019).

These promising results already underlined the usefulness of eye tracking indexes to renew the exploration of cognitive functions in FASD and offered crucial insights into this research field. The current literature nevertheless presents some limitations, which lead us to propose several perspectives for future studies. The first category of perspectives is related to the selection of the population with FASD and to the control of potentially biasing variables. Indeed, the reviewed studies are characterized by a large heterogeneity regarding the FASD diagnosis tools (e.g., Astley and Clarren, 2000; Chudley et al., 2005) and inclusion criteria used, some authors (e.g., Green et al., 2007) even using imprecise terms (e.g., "fetal alcohol effects") to characterize their population. The difficulty to recruit large samples of FASD patients, as well as the complexity to perform precise differential diagnosis between FASD subtypes, justify such heterogeneity in past studies. However, the first recommendation for future studies would thus be, as proposed in recent review papers (Garrison et al., 2019; Mattson et al., 2019), to systematically use gold-standard diagnosis procedures (e.g., Cook et al., 2016; McQuire et al., 2016) including, beyond DSM-5 criteria, fine-grained assessment tools (e.g., Hoyme et al., 2016) to ensure the comparability in the FASD populations selected across studies, and thus in the results obtained. This procedure might actually be complemented by the screening tools described in this review (Tseng et al., 2013; Zhang et al., 2019), capitalizing on eye tracking measures to refine FASD detection. A second 
recommendation for future studies is to improve the control on biasing variables potentially influencing eye tracking indexes. Previous studies did not control participants' alcohol consumption, which appears acceptable when focusing on young children but might be an issue among adolescent populations. The mean age of participants in all studies exploring FASD was around 12 years old (several studies including 15-17 yearold adolescents), and it can thus not be excluded that a proportion of the included adolescents had previous alcohol consumption or even heavy/binge drinking habits. Indeed, such habits are frequently observed in early adolescence (WHO, 2018) and children of parents with alcohol-use disorders are particularly vulnerable to early alcohol consumption (Rossow et al., 2016a; 2016b). As acute (see Maurage et al., 2020 for a recent review) or heavy (e.g., Iacono et al., 2000; McAteer, 2015; 2018) alcohol drinking in youth is known to have a strong influence on eye tracking measures, personal alcohol consumption could influence the results obtained in FASD studies. The systematic evaluation of current alcohol consumption, at least through widely used and easy implementable tools (e.g., Alcohol Use Identification Test, Saunders et al., 1993; Brief Michigan Alcohol Screening Test, Pokorny et al., 1972; Timeline Follow-Back, Sobell and Sobell, 1992) could be included in all FASD using eye tracking. This would ensure that adolescents with FASD are teetotalers, and thus that the results observed are related to prenatal alcohol exposure and not to recent personal alcohol consumption. Moreover, as FASD is co-occurring with more than 400 other conditions encompassing physical (e.g., congenital malformations) but also mental (e.g., intellectual disabilities, behavioral disorders, psychiatric comorbidities) health problems (Popova et al., 2016), upcoming studies should reinforce the evaluation of these comorbidities to disentangle the respective influence of FASD and of disorders frequently co-occurring with FASD.

The second category of research perspectives is related to the eye tracking indexes used and to their links with underlying cognitive processes. With the notable exception of the 
two papers developing screening tools (Tseng et al., 2013; Zhang et al., 2019, which capitalized on a wide range of eye tracking indexes) and while seven studies had the merit to combine eye tracking measures with neuroscience tools, all studies were based on a unique set of tasks (i.e., prosaccade, antisaccade and/or memory-guided tasks) and on a very limited range of eye tracking measures (i.e., saccadic reaction time, saccadic velocity/amplitude, premature/express saccades or saccadic direction errors), allowing the exploration of a small amount of cognitive processes, namely perception (being the central focus of $47 \%$ of the studies), memory (20\%) and inhibition (20\%). On the one hand, this limited exploration has left major cognitive abilities unexplored, despite the fact that eye tracking measures have recently been fruitfully used to explore other key processes in alcohol-related disorders. For example, several studies have used the visual probe task to measure the eye movements associated with the attentional bias towards alcohol-related stimuli in alcohol intoxication (e.g., Fernie et al., 2012; Schoenmakers et al., 2008) or chronic alcohol use disorders (e.g., Field et al., 2011; McAteer et al., 2018). This allowed to renew the understanding of this deficit, largely explored at the behavioral level (Fadardi et al., 2016; Field and Cox, 2008) and constituting a key component of addictive disorders models (Field et al., 2010; Wiers et al., 2015). In the same vein, other eye tracking indexes (e.g., pupillary diameter) have been used to explore emotional processing in alcohol-related disorders (Claisse et al., 2016), such deficits having an important role in this condition (Kornreich et al., 2002; Zywiak et al., 2003), but also in FASD (Kerns et al., 2016). Future studies should thus go beyond the reduced range of paradigms and indexes used up to now to deepen the knowledge on eye movements deficits in FASD.

On the other hand, while the studies included in this review have determined the links between eye tracking indexes and underlying cognitive processes (some of them even investigating their brain correlates), such links should be further explored in upcoming 
works. Indeed, eye tracking techniques measure eye movements (e.g., fixation, saccade) and gaze location, but these indexes are not perfectly reflecting the underlying cognitive abilities. First, they only capture the foveal vision and do not index peripheral retina processing, which might be impaired in FASD (as several studies have indexed a deficit to detect peripheral stimuli and orient gaze towards them). Second, the interpretation of the eye tracking indexes related to high-level cognitive functions should consider the influence of low-level processes, and vice-versa: all indexes are simultaneously influenced by bottom-up (e.g., stimuli brightness, color, movement) and top-down (e.g., previous experience, memory, inhibition) factors. Regarding the paradigms used in FASD, the usual assumption is that the prosaccade task measures perceptive/oculomotor abilities (mostly through the estimation of saccadic reaction times) while the memoryguided and antisaccade tasks index memory and inhibition abilities (by respectively measuring the ability to perform saccades towards a previously memorized location and to inhibit/reprogram saccades). However, as rightly stressed by Coffman et al (2013), saccadic eye movement is based on the activation of a quite large brain network, encompassing low-level (e.g., visual processing in the primary visual cortex) but also high-level (e.g., spatial location processing in the parietal cortex) steps (Colby et al., 1996; Moon et al., 2007). It can thus not be excluded that the perceptive deficits reported in the available studies might be influenced by the memory or executive dysfunctions also observed in FASD (e.g., through erroneous anticipations due to impaired inhibitory control). Conversely, the memory or executive deficits measured in memory-guided or antisaccade tasks might be partly relying on lower level impairment (e.g., global modifications of saccadic speed). Future studies should, therefore, determine the exact nature of eye movements disorders in FASD, by disentangling the often multiple cognitive processes involved in each paradigm. Such explorations will notably clarify whether saccadic dysfunctions are mostly explained by low-level perceptivo-motor impairments, 
or rather by reduced attentional, memory or executive functions, with potential preservation of the motor component underlying saccadic movements, as reported in some studies (Coffman et al., 2013; Stephen et al., 2013).

A last and central limit related to the available literature is the lack of diversity in the groups exploring this research field as, among the 15 studies considered in this review, 11 were from the same laboratory (i.e., Center for Neuroscience Studies, Queen's University, Kingston, Canada) and two (Tseng et al., 2013; Zhang et al., 2019) included researchers from this laboratory. These studies are characterized by a strong coherence, as they repeatedly identified behavioral and eye tracking deficits in FASD. However, this coherence might at least partly result from the overlap in the experimental designs (i.e., systematic use of the saccade task, with prosaccade, antisaccade and/or memory-guided saccades conditions) and samples used across studies. It is suggested in some papers (Paolozza et al., 2015; 2016; Zhang et al., 2019) that the same cohort was used in various studies, but the authors do not systematically state the extent of this overlap, nor the potential use of identical datasets or results. Some idiosyncrasies of this cohort (e.g., cognitive abilities, psychopathological comorbidities) might explain the repeatedly described eye tracking deficits and lower their generalizability to the whole FASD population. The two studies from other laboratories (Coffman et al., 2013; Stephen et al., 2013) did not index any deficit in eye tracking measures in FASD, which further reinforces the proposal that a sample bias might explain some of the deficits previously reported for perceptive, memory and executive functions in FASD. The replication of these results using other samples and paradigms should thus constitute a priority.

\section{Conclusion}


This review first showed that eye tracking studies on FASD have demonstrated that this disorder is related to impairments for perceptive (i.e., increased saccadic reaction times), working memory (i.e., lower accuracy and increased errors in memory-guided saccadic eye movements) and executive (i.e., reduced saccadic inhibitory control) abilities. Then, capitalizing on a rigorous methodological quality assessment and on a critical evaluation of the available data, we have identified the main weaknesses related to previous studies, mostly concerning the population selection criteria, the control of biasing variables, the limited variety of eye tracking measures, and the over-interpretation of the cognitive correlates of eye tracking indexes. We have also underlined that an important issue for this research field is the fact that the vast majority of the studies have been conducted in the same research group, and at least partly on the same dataset. For each of these limits, we have proposed solutions that could be implemented in future studies (including the replication of the available results by other research groups and in other samples), together with preliminary guidelines promoting the emergence of methodological goldstandards. This paper should thus be considered as a first step towards an optimization of eye movements' measures in FASD, which could allow eye tracking to become an important tool in the exploration of this disorder. 


\section{Declaration of interest}

The authors declare no conflict of interest.

\section{Acknowledgments}

Pierre Maurage (Senior Research Associate) and Zoé Bollen (Research Assistant) are funded by the Belgian Fund for Scientific Research (F.R.S.-FNRS, Belgium). Nicolas Masson is a post-doctoral researcher funded by grant PDR-FNRS T.0047.18 and by the National Research Fund of Luxembourg. This research has been supported by a grant from the Fondation pour la Recherche en Alcoologie (FRA, France). 


\section{References}

American Psychiatric Association, 2013. Diagnostic and Statistical Manual of Mental Disorders, 5 Edn. Arlington, VA: American Psychiatric Association.

Aragón, A.S., Kalberg, W.O., Buckley, D., Barela-Scott, L.M., Tabachnick, B.G., May, P.A., 2008. Neuropsychological study of FASD in a sample of American Indian children: processing simple versus complex information. Alcohol. Clin. Exp. Res. 32:2136-2148. http://doi.org/10.1111/j.1530-0277.2008.00802.x.

Astley, S.J., Clarren, S.K., 2000. Diagnosing the full spectrum of fetal alcohol-exposed individuals: Introducing the 4-digit diagnostic code. Alcohol. 35:400-410. http://doi.org/10.1093/alcalc/35.4.400

Baird-Gunning, J.J.D., Lueck, C.J., 2018. Central control of eye movements. Curr. Opin. Neurol. 31:90-95. http://doi.org/10.1097/WCO.0000000000000514

Beh, S.C., Frohman, T.C., Frohman, E.M., 2017. Cerebellar control of eye movements. J. Neuroophthalmol. 37:87-98. http://doi.org/10.1097/WNO.0000000000000456

Bertrand, J., Floyd, L.L., Weber, M.K.; Fetal Alcohol Syndrome Prevention Team, Division of Birth Defects and Developmental Disabilities, National Center on Birth Defects and Developmental Disabilities, Centers for Disease Control and Prevention (CDC), 2005. Guidelines for identifying and referring persons with fetal alcohol syndrome. MMWR Recomm. Rep. 54:1-14. 
Bjork, J.M., Gilman, J.M., 2014. The effects of acute alcohol administration on the human brain: insights from neuroimaging. Neuropharmacology 84:101-110. http://doi.org/10.1016/j.neuropharm.2013.07.039

Black, M.H., Chen, N.T.M., Iyer, K.K., Lipp, O.V., Bölte, S., Falkmer, M., Tan, T., Girdler, S., 2017. Mechanisms of facial emotion recognition in autism spectrum disorders: Insights from eye tracking and electroencephalography. Neurosci. Biobehav. Rev. 80:488-515. http://doi.org/10.1016/j.neubiorev.2017.06.016

Bolaños, A.D., Coffman, B.A., Candelaria-Cook, F.T., Kodituwakku, P., Stephen, J.M., 2017. Altered neural oscillations during multisensory integration in adolescents with Fetal Alcohol Spectrum Disorder. Alcohol. Clin. Exp. Res. 41:2173-2184. http://doi.org/10.1111/acer.13510

Bühler, M., Mann, K., 2011. Alcohol and the human brain: A systematic review of different neuroimaging methods. Alcohol. Clin. Exp. Res. 35:1771-1793. http://doi.org/10.1111/j.1530-0277.2011.01540.x

Carbia, C., López-Caneda, E., Corral, M., Cadaveira, F., 2018. A systematic review of neuropsychological studies involving young binge drinkers. Neurosci. Biobehav. Rev. 90:332-349. http://doi.org/10.1016/j.neubiorev.2018.04.013

Chudley, A.E., Conry, J., Cook, J.L., Loock, C., Rosales, T., LeBlanc, N., Public Health Agency of Canada's National Advisory Committee on Fetal Alcohol Spectrum 
Disorder, 2005. Fetal alcohol spectrum disorder: Canadian guidelines for diagnosis. CMAJ 172:S1-S21. http://doi.org/ 10.1503/cmaj.1040302

Claisse, C., Lewkowicz, D., Cottencin, O., Nandrino, J.-L., 2016. Overactivation of the pupillary response to emotional information in short- and long-term alcohol abstinent patients. Alcohol. 51:670-676. http://doi.org/10.1093/alcalc/agw015

Coe, B.C., Munoz, D.P., 2017. Mechanisms of saccade suppression revealed in the antisaccade task. Philos. Trans. R. Soc. Lond. B. Biol. Sci. 372:20160192. http://doi.org/10.1098/rstb.2016.0192

Coffman, B.A., Kodituwakku, P., Kodituwakku, E.L., Romero, L., Sharadamma, N.M., Stone, D., Stephen, J.M., 2013. Primary visual response (M100) delays in adolescents with FASD as measured with MEG. Hum. Brain Mapp. 34:2852-2862. http://doi.org/10.1002/hbm.22110

Colby, C.L., Duhamel, J.R., Goldberg, M.E., 1996. Visual, presaccadic, and cognitive activation of single neurons in monkey lateral intraparietal area. J. Neurophys. 76:2841-2852. http://doi.org/10.1152/jn.1996.76.5.2841

Cook, J.L., Green, C.R., Lilley, C.M., Anderson, S.M., Baldwin, M..E, Chudley, A.E., Conry, J.L., LeBlanc, N., Loock, C.A., Lutke, J., Mallon, B.F., McFarlane, A.A., Temple, V.K., Rosales, T., Canada Fetal Alcohol Spectrum Disorder Research Network, 2016. Fetal alcohol spectrum disorder: a guideline for diagnosis across the lifespan. CMAJ, 188:191-197. http://doi.org/10.1503/cmaj.141593 
Crocker, N., Vaurio, L., Riley, E.P., Mattson, S.N., 2011. Comparison of verbal learning and memory in children with heavy prenatal alcohol exposure or attentiondeficit/hyperactivity disorder. Alcohol. Clin. Exp. Res. 35:1114-1121. http://doi.org/10.1111/j.1530-0277.2011.01444.x

Day, N. L., Helsel, A., Sonon, K., Goldschmidt, L., 2013. The association between prenatal alcohol exposure and behavior at 22 years of age. Alcohol. Clin. Exp. Res. 37:1171-1178. http://doi.org/10.1111/acer.12073

Diwadkar, V.A., Meintjes, E.M., Goradia, D., Dodge, N.C., Warton, C., Molteno, C.D., Jacobson, S.W., Jacobson, J.L., 2013. Differences in cortico-striatal-cerebellar activation during working memory in syndromal and nonsyndromal children with prenatal alcohol exposure. Hum. Brain Mapp. 34:1931-1945. http://doi.org/10.1002/hbm.22042

Donald, K.A., Eastman, E., Howells, F.M., Adnams, C., Riley, E.P., Woods, R.P., Narr, K.L., Stein, D.J., 2015. Neuroimaging effects of prenatal alcohol exposure on the developing human brain: a magnetic resonance imaging review. Acta Neuropsychiatr. 27:251-269. http://doi.org/10.1017/neu.2015.12

Doney, R., Lucas, B.R., Jones, T., Howat, P., Sauer, K., Elliott, E.J., 2014. Fine motor skills in children with prenatal alcohol exposure or fetal alcohol spectrum disorder. J. Dev. Behav. Pediatr. 35:598-609. http://doi.org/10.1097/DBP.0000000000000107 
Dorris, M.C., Pare, M., Munoz, D.P., 2000. Immediate neural plasticity shapes motor performance. J. Neurosci. 20:RC52

Eckstein, M.K., Guerra-Carrillo, B., Miller Singley, A.T., Bunge, S.A., 2017. Beyond eye gaze: What else can eyetracking reveal about cognition and cognitive development? Dev. Cogn. Neurosci. 25:69-91. http://doi.org/10.1016/j.dcn.2016.11.001

Fadardi, J.S., Cox, W.M., Rahmani, A., 2016. Neuroscience of attentional processes for addiction medicine: from brain mechanisms to practical considerations. Prog. Brain Res. 223:77-89. http://doi.org/10.1016/bs.pbr.2015.08.002

Fernie, G., Christiansen, P., Cole, J.C., Rose, A.K., Field, M., 2012. Effects of 0.4 g/kg alcohol on attentional bias and alcohol-seeking behaviour in heavy and moderate $\begin{array}{llll}\text { social drinkers. } & \text { J. } & \text { Psychopharmacol. } & \text { 26:1017-1025. }\end{array}$ http://doi.org/10.1177/0269881111434621

Field, M., Cox, W.M., 2008. Attentional bias in addictive behaviors: a review of its development, causes, and consequences. Drug Alcohol Depend. 97:1-20. http://doi.org/10.1016/j.drugalcdep.2008.03.030

Field, M., Hogarth, L., Bleasdale, D., Wright, P., Fernie, G., Christiansen, P., 2011. Alcohol expectancy moderates attentional bias for alcohol cues in light drinkers. Addiction 106:1097-1103. http://doi.org/10.1111/j.1360-0443.2011.03412.x

Field, M., Wiers, R.W., Christiansen, P., Fillmore, M.T., Verster, J.C., 2010. Acute alcohol effects on inhibitory control and implicit cognition: implications for loss of control over 
drinking. Alcohol Clin. Exp. Res. 34:1346-1352. http://doi.org/10.1111/j.15300277.2010.01218.x

Garrison, L., Morley, S., Chambers, C.D., Bakhireva, L.N., 2019. Forty years of assessing neurodevelopmental and behavioral effects of prenatal alcohol exposure in infants: What have we learned? Alcohol. Clin. Exp. Res. 43:1632-1642. http://doi.org/10.1111/acer.14127

Gautam, P., Lebel, C., Narr, K.L., Mattson, S.N., May, P.A., Adnams, C.M., Riley, E.P., Jones, K.L., Kan, E.C., Sowell, E.R., 2015. Volume changes and brain-behavior relationships in white matter and subcortical gray matter in children with prenatal alcohol exposure. Hum. Brain Mapp. 36:2318-2329. http://doi.org/10.1002/hbm.22772

Gerhold, M.M., Jacobson, S.W., Jacobson, J.L., Molteno, C.D., Meintjes, E.M., Andrew, C.M., 2017. An ERP study of response inhibition in the auditory domain in children with Fetal Alcohol Spectrum Disorders. Alcohol. Clin. Exp. Res. 41:96-106. http://doi.org/10.1111/acer.13263

Green, C.R., Lebel, C., Rasmussen, C., Beaulieu, C., Reynolds, J.N., 2013. Diffusion tensor imaging correlates of saccadic reaction time in children with fetal alcohol spectrum disorder. Alcohol Clin. Exp. Res. 37:1499-1507. http://doi.org/10.1111/acer.12132

Green, C.R., Mihic, A.M., Brien, D.C., Armstrong, I.T., Nikkel, S.M., Stade, B.C., Rasmussen, C., Munoz, D.P., Reynolds, J.N., 2009. Oculomotor control in children 
with fetal alcohol spectrum disorders assessed using a mobile eye tracking laboratory. Eur. J. Neurosci. 29:1302-1309. http://doi.org/10.1111/j.14609568.2009 .06668

Green, C.R., Munoz, D.P., Nikkel, S.M., Reynolds, J.N., 2007. Deficits in eye movement control in children with fetal alcohol spectrum disorders. Alcohol. Clin. Exp. Res. 31:500-511. http://doi.org/10.1111/j.1530-0277.2006.00335.x

Hemington, K.S., Reynolds, J.N., 2014. Electroencephalographic correlates of working memory deficits in children with Fetal Alcohol Spectrum Disorder using a singleelectrode pair recording device. Clin. Neurophysiol. 125:2364-2371. http://doi.org/10.1016/j.clinph.2014.03.025

Hofer, R., Burd, L., 2009. Review of published studies of kidney, liver, and gastrointestinal birth defects in fetal alcohol spectrum disorders. Birth Defects Res. A. Clin. Mol. Teratol. 85:179-183. http://doi.org/10.1002/bdra.20562.

Hoyme, H.E., Kalberg, W.O., Elliott, A.J., Blankenship, J., Buckley, D., Marais, A.S., Manning, M.A., Robinson, L.K., Adam, M.P., Abdul-Rahman, O., Jewett, T., Coles, C.D., Chambers, C., Jones, K.L., Adnams, C.M., Shah, P.E., Riley, E.P., Charness, M.E., Warren, K.R., May, P.A., 2016. Updated clinical guidelines for diagnosing fetal alcohol spectrum disorders. Pediatrics 138:e20154256. http://doi.org/10.1542/peds.2015-4256 
Iacono, W.G., Carlson, S.R., Malone, S.M., 2000. Identifying a multivariate endophenotype for substance use disorders using psychophysiological measures. Int. J.Psychophysiol. 38:81-96. http://doi.org/10.1016/s0167-8760(00)00132-x

Jones, D.K., Knösche, T.R., Turner, R., 2013. White matter integrity, fiber count, and other fallacies: the do's and don'ts of diffusion MRI. Neuroimage 73:239-254. http://doi.org/10.1016/j.neuroimage.2012.06.081

Kerns, K.A., Siklos, S., Baker, L., Müller, U., 2016. Emotion recognition in children with Fetal Alcohol Spectrum Disorders. Child Neuropsychol 22:255-275. http://doi.org/10.1080/09297049.2014.993310

Khoury, J.E., Milligan, K., Girard, T.A., 2015. Executive functioning in children and adolescents prenatally exposed to alcohol: A meta-analytic review. Neuropsychol. Rev. 25:149-170. http://doi.org/10.1007/s11065-015-9289-6

Kodituwakku, P. W. 2009. Neurocognitive profile in children with fetal alcohol spectrum disorders. Dev. Disabil. Res. Rev. 15:218-224. http://doi.org/10.1002/ddrr.73

Kornreich, C., Philippot, P., Foisy, M.-L., Blairy, S., Raynaud, E., Dan, B., Hess, U., Noël, X., Pelc, I., Verbanck, P., 2002. Impaired emotional facial expression recognition Is associated With interpersonal problems in alcoholism. Alcohol Alcohol. 37:394-400. http://doi.org/10.1093/alcalc/37.4.394 
Kunimatsu, J., Suzuki, T.W., Tanaka, M., 2016. Implications of lateral cerebellum in proactive control of saccades. J. Neurosci. 36:7066-7074. http://doi.org/10.1523/JNEUROSCI.0733-16.2016

Lebel, C., Roussotte, F., Sowell, E.R., 2011. Imaging the impact of prenatal alcohol exposure on the structure of the developing human brain. Neuropsychol. Rev. 21:102-118. http://doi.org/10.1007/s11065-011-9163-0

Leigh, R.J., Kennard, C., 2004. Using saccades as a research tool in the clinical neurosciences. Brain 127:460-477. http://doi.org/10.1093/brain/awh035

Liberati, A., Altman, D.G., Tetzlaff, J., Mulrow, C., Gøtzsche, P.C., Ioannidis, J.P., Clarke, M., Devereaux, P.J., Kleijnen, J., Moher, D., 2009. The PRISMA statement for reporting systematic reviews and meta-analyses of studies that evaluate health care interventions: explanation and elaboration. PLoS Med. 6:e1000100. http://doi.org/10.1371/journal.pmed.1000100

Lisberger, S.G., 2010. Visual guidance of smooth-pursuit eye movements: Sensation, action, and what happens in between. Neuron 66:477-491. http://doi.org/10.1016/j.neuron.2010.03.027

Luna, B., Velanova, K., Geier, C.F., 2008. Development of eye-movement control. Brain Cogn. 68:293-308. http://doi.org/10.1016/j.bandc.2008.08.019 
Mattson, S.N., Bernes, G.A., Doyle, L.R., 2019. Fetal Alcohol Spectrum Disorders: A review of the neurobehavioral deficits associated with prenatal alcohol exposure. Alcohol. Clin. Exp. Res. 43:1046-1062. http://doi.org/10.1111/acer.14040

Maurage, P., Masson N., Bollen, Z., D'Hondt, F., 2020. Eye tracking correlates of acute alcohol consumption: A systematic and critical review. Neurosci. Biobehav. Rev. 108:400-422. http://doi.org/10.1016/j.neubiorev.2019.10.001

McAteer, A. M., Curran, D., Hanna, D., 2015. Alcohol attention bias in adolescent social drinkers: an eye tracking study. Psychopharmacology (Berl) 232:3183-3191. http://doi.org/10.1007/s00213-015-3969-z

McAteer, A.M., Hanna, D., Curran, D., 2018. Age-related differences in alcohol attention bias: a cross-sectional study. Psychopharmacology (Berl) 235:2387-2393. http://doi.org/10.1007/s00213-018-4935-3

McGee, C.L., Bjorkquist, O.A., Riley, E.P., Mattson, S.N., 2009. Impaired language performance in young children with heavy prenatal alcohol exposure. Neurotoxicol. Teratol. 31:71-75. http://doi.org/10.1016/j.ntt.2008.09.004

McQuire, C., Paranjothy, S., Hurt, L., Mann, M., Farewell, D., Kemp, A., 2016. Objective measures of prenatal alcohol exposure: A systematic review. Pediatrics, 138: e20160517. http://doi.org/10.1542/peds.2016-0517 
Moher, D., Liberati, A., Tetzlaff, J., Altman, D.G.; PRISMA Group, 2009. Preferred reporting items for systematic reviews and meta-analyses: the PRISMA statement. PLoS Med. 6:e1000097. http://doi.org/10.1371/journal.pmed.1000097

Moon, S.Y., Barton, J.J.S., Mikulski, S., Polli, F.E., Cain, M.S., Vangel, M., Hamalainen, M.S., Manoach, D.S., 2007. Where left becomes right: a magnetoencephalographic study of sensorimotor transformation for antisaccades. Neuroimage 36:1313-1323. http://doi.org/10.1016/j.neuroimage.2007.04.040

Moore, E.M., Migliorini, R., Infante, M.A., Riley, E.P., 2014. Fetal Alcohol Spectrum Disorders: Recent neuroimaging findings. Curr. Dev. Disord. Rep. 1:161-172. http://doi.org/10.1007/s40474-014-0020-8

Myrie, S.B., Pinder, M.A., 2018. Skeletal muscle and fetal alcohol spectrum disorder. Biochem. Cell. Biol. 96:222-229. http://doi.org/10.1139/bcb-2017-0118.

National Heart, Lung, and Blood Institute, 2014. Quality Assessment Tool for Observational Cohort and Cross-Sectional Studies. Available at: National Heart, Lung, and Blood Institute, Bethesda, MD. http://www.nhlbi.nih.gov/healthpro/guidelines/in-develop/cardiovascular-risk-reduction/tools/cohort.

Norman, A.L., Crocker, N., Mattson, S.N., Riley, E.P., 2009. Neuroimaging and fetal alcohol spectrum disorders. Dev. Disabil. Res. Rev. 15:209-217. http://doi.org/10.1002/ddrr.72 
Paolozza, A., Munn, R., Munoz, D.P., Reynolds, J.N., 2015. Eye movements reveal sexually dimorphic deficits in children with fetal alcohol spectrum disorder. Front. Neurosci. 9:76. http://doi.org/10.3389/fnins.2015.00076

Paolozza, A., Munoz, D.P., Brien, D., Reynolds, J.N., 2016. Immediate neural plasticity involving reaction time in a saccadic eye movement task is intact in children with fetal alcohol spectrum disorder. Alcohol. Clin. Exp. Res. 40:2351-2358. http://doi.org/10.1111/acer.13224

Paolozza, A., Rasmussen, C., Pei, J., Hanlon-Dearman, A., Nikkel, S.M., Andrew, G., McFarlane, A., Samdup, D., Reynolds, J.N., 2014a. Working memory and visuospatial deficits correlate with oculomotor control in children with fetal alcohol spectrum disorder. Behav. Brain Res. 263:70-79. http://doi.org/10.1016/j.bbr.2014.01.024

Paolozza, A., Rasmussen, C., Pei, J., Hanlon-Dearman, A., Nikkel, S.M., Andrew, G., McFarlane, A., Samdup, D., Reynolds, J.N., 2014b. Deficits in response inhibition correlate with oculomotor control in children with fetal alcohol spectrum disorder and prenatal alcohol exposure. Behav. Brain Res. 259:97-105. http://doi.org/10.1016/j.bbr.2013.10.040

Paolozza, A., Titman, R., Brien, D., Munoz, D.P., Reynolds, J.N., 2013. Altered accuracy of saccadic eye movements in children with fetal alcohol spectrum disorder. Alcohol. Clin. Exp. Res. 37:1491-1498. http://doi.org/10.1111/acer.12119 
Paolozza, A., Treit, S., Beaulieu, C., Reynolds, J.N., 2014c. Response inhibition deficits in children with Fetal Alcohol Spectrum Disorder: relationship between diffusion tensor imaging of the corpus callosum and eye movement control. Neuroimage Cli. 5:53-61. http://doi.org/10.1016/j.nicl.2014.05.019

Paolozza, A., Treit, S., Beaulieu, C., Reynolds, J.N., 2017. Diffusion tensor imaging of white matter and correlates to eye movement control and psychometric testing in children with prenatal alcohol exposure. Hum. Brain Mapp. 38:444-456. http://doi.org/10.1002/hbm.23371

Pokorny, A.D., Miller, B.A., Kaplan, H.B., 1972. The brief MAST: A shortened version of the Michigan Alcoholism Screening Test. Amer. J. Psychiat. 129:342-345. http://doi.org/10.1176/ajp.129.3.342

Popa, L., Selejan, O., Scott, A., Mureşanu, D. F., Balea, M., Rafila, A., 2015. Reading beyond the glance: eye tracking in neurosciences. Neurol. Sci. 36:683-688. http://doi.org/10.1007/s10072-015-2076-6

Popova, S., Lange, S., Shield, K., Mihic, A., Chudley, A.E., Mukherjee, R.A.S., Bekmuradov, D., Rehm, J., 2016. Comorbidity of fetal alcohol spectrum disorder: a systematic review and meta-analysis. Lancet 387:978-987. http://doi.org/10.1016/S0140-6736(15)01345-8

Rasmussen, C., 2005. Executive functioning and working memory in fetal alcohol spectrum disorder. Alcohol. Clin. Exp. Res. 29:1359-1367. http://doi.org/10.1097/01.alc.0000175040.91007.d0 
Ribeiro, I.M., Vale, P.J., Tenedorio, P.A., Rodrigues, P.A., Bilhoto, M.A., Pereira, H.C., 2007. Ocular manifestations in fetal alcohol syndrome. Eur. J. Ophthalmol. 17:104109. http://doi.org/10.1177/112067210701700114

Rossow, I., Felix, L., Keating, P., McCambridge, J., 2016a. Parental drinking and adverse outcomes in children: A scoping review of cohort studies. Drug Alcohol. Rev. 35:397-405. http://doi.org/10.1111/dar.12319

Rossow, I., Keating, P., Felix, L., McCambridge, J., 2016b. Does parental drinking influence children's drinking? A systematic review of prospective cohort studies. Addiction 111:204-217. http://doi.org/10.1111/add.13097

Saunders, J.B., Aasland, O.G., Babor, T.F., de la Puente, J.R., Grant, M, 1993. Development of the Alcohol Use Disorders Screening Test (AUDIT). WHO collaborative project on early detection of persons with harmful alcohol consumption II. Addiction 88:791-804. http://doi.org/10.1111/j.1360-0443.1993.tb02093.x

Schoenmakers, T., Wiers, R.W., Field, M., 2008. Effects of a low dose of alcohol on cognitive biases and craving in heavy drinkers. Psychopharmacology (Berl) 197:169-178. http://doi.org/10.1007/s00213-007-1023-5

Shaikh, A.G., Zee, D.S., 2018. Eye movement research in the twenty-first century - a window to the brain, mind, and more. Cerebellum 17:252-258. http://doi.org/10.1007/s12311-017-0910-5. 
Sobell, L., Sobell, M., 1992. Timeline follow-back: a technique for assessing self-reported alcohol consumption. In: Litten, R., Allen, J. (Eds.), Measuring Alcohol Consumption: Psychosocial and Biochemical Methods. Humana Press, Totowa, N.J., pp. 41-72.

Stavro, K., Pelletier, J., Potvin, S., 2013. Widespread and sustained cognitive deficits in alcoholism: a meta-analysis: Alcoholism and cognition. Addict. Biol., 18:203-213. http://doi.org/10.1111/j.1369-1600.2011.00418.x

Stephen, J.M., Coffman, B.A., Stone, D.B., Kodituwakku, P., 2013. Differences in MEG gamma oscillatory power during performance of a prosaccade task in adolescents with FASD. Front. Hum. Neurosci. 7:900. http://doi.org/10.3389/fnhum.2013.00900

Tseng, P.H., Cameron, I.G., Pari, G., Reynolds, J.N., Munoz, D.P., Itti, L., 2013. Highthroughput classification of clinical populations from natural viewing eye movements. J. Neurol. 260:275-284. http://doi.org/10.1007/s00415-012-6631-2

Vaurio, L., Riley, E.P., Mattson, S.N., 2011. Neuropsychological comparison of children with heavy prenatal alcohol exposure and an IQ-matched comparison group. J. Int. Neuropsychol. Soc. 17:463-473. http://doi.org/10.1017/S1355617711000063

Wardak, C., Olivier, E., Duhamel, J.R., 2011. The relationship between spatial attention and saccades in the frontoparietal network of the monkey. Eur. J. Neurosci. 33:1973-1981. http://doi.org/10.1111/j.1460-9568.2011.07710.x 
Wiers, R.W., Boelema, S.R., Nikolaou, K., Gladwin, T.E., 2015. On the development of implicit and control processes in relation to substance use in adolescence. Curr. Addict. Rep. 2:141-155. http://doi.org/10.1007/s40429-015-0053-z

World Health Organization (Ed.), 2018. Global status report on alcohol and health 2018. Geneva, Switzerland: World Health Organization.

Yang, J., Qiu, H., Qu, P., Zhang, R., Zeng, L., Yan, H., 2015. Prenatal alcohol exposure and congenital heart defects: A meta-analysis. PLoS One 10:e0130681. http://doi.org/10.1371/journal.pone.0130681.

Zhang, C., Paolozza, A., Tseng, P.H., Reynolds, J.N., Munoz, D.P., Itti, L., 2019. Detection of children/youth with Fetal Alcohol Spectrum Disorder through eye movement, psychometric, and neuroimaging data. Front. Neurol. 10:80. http://doi.org/10.3389/fneur.2019.00080

Zywiak, W.H., Westerberg, V.S., Connors, G.J., Maisto, S.A., 2003. Exploratory findings from the Reasons for Drinking Questionnaire. J. Subst. Abuse Treat. 25:287-292. http://doi.org/10.1016/S0740-5472(03)00118-1 


\section{Figure Caption}

Figure 1. PRISMA flow diagram describing the selection process of the papers included. 


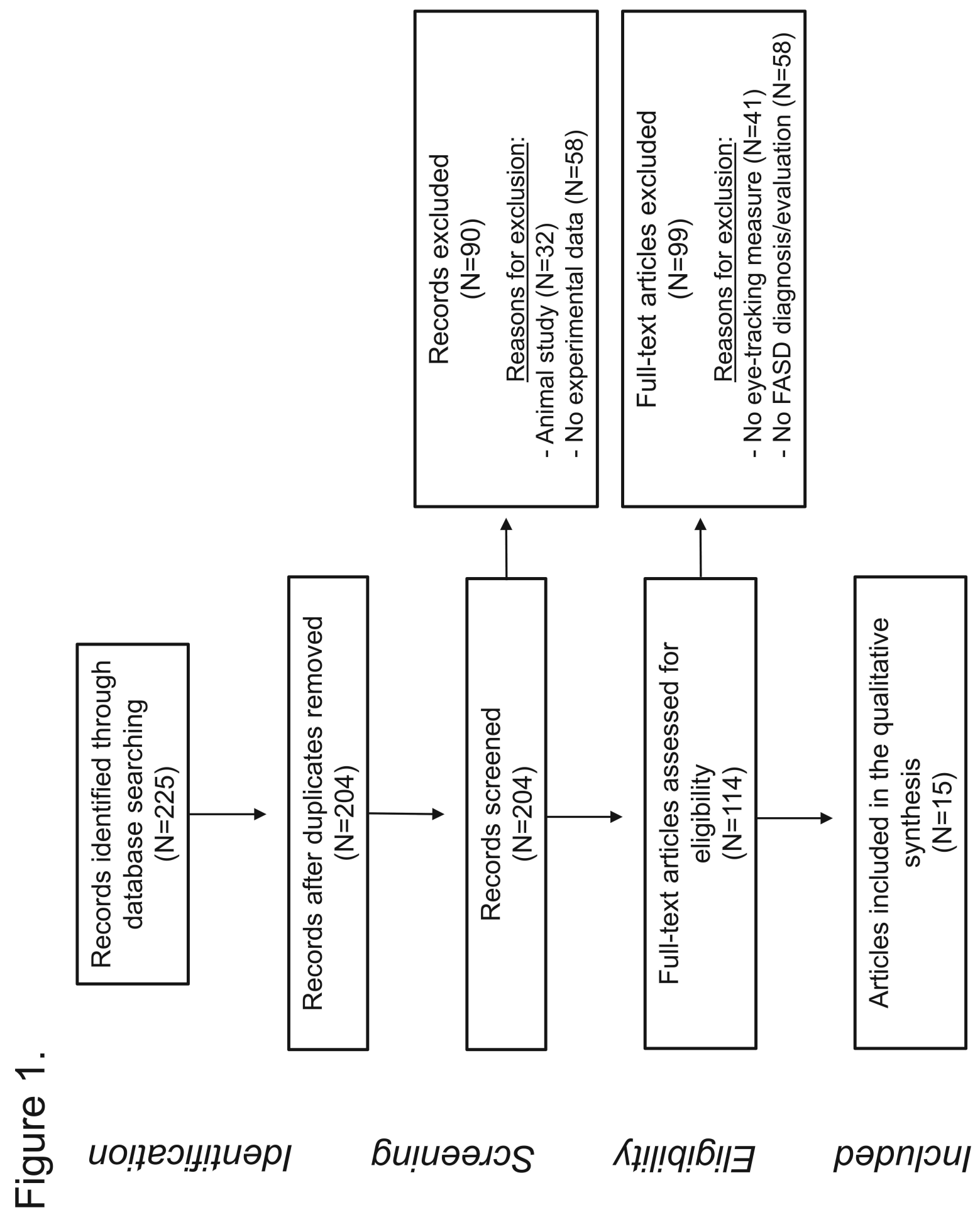


Table 1. Description and main results of eye tracking studies on fetal alcohol spectrum disorder.

\begin{tabular}{|c|c|c|c|c|c|c|c|c|c|c|c|c|c|c|c|c|c|}
\hline \multirow[b]{2}{*}{ Authors (year) } & \multicolumn{4}{|c|}{ Population } & \multicolumn{3}{|c|}{ Exposures } & \multicolumn{2}{|c|}{ Comparator } & \multicolumn{5}{|c|}{ Design } & \multicolumn{3}{|c|}{ Outcomes } \\
\hline & Sample $(N)$ & $\begin{array}{l}A g e \\
{[M(s d)]}\end{array}$ & \begin{tabular}{|c} 
Gender \\
ratio \\
$(\%$ males
\end{tabular} & $\begin{array}{c}\text { Exclusion } \\
\text { criteria }\end{array}$ & \begin{tabular}{|c} 
Diagnosis I \\
Characteristics
\end{tabular} & $\begin{array}{l}\text { Alcohol } \\
\text { measure }\end{array}$ & Comorbidities & $\begin{array}{l}\text { Control } \\
\text { group }\end{array}$ & $\left|\begin{array}{l}\text { Matching } \\
\text { variables }\end{array}\right|$ & $\begin{array}{l}\text { Processes } \\
\text { measured }\end{array}$ & Tasks & Stimuli & $\begin{array}{l}\text { Eye tracking } \\
\text { indexes }\end{array}$ & \begin{tabular}{|c|} 
Eye tracking \\
materials / Sampling \\
rate
\end{tabular} & Main eye tracking results & Limitations & Key conclusions \\
\hline $\begin{array}{l}\text { Coffman et al. } \\
(2013)\end{array}$ & 16 & $\begin{array}{l}15.2 \\
(2.6)\end{array}$ & $67 \%$ & $\begin{array}{l}\text { No FASD } \\
\text { diagnosis }\end{array}$ & FASD & NR & NR & $20 \mathrm{HC}$ & \begin{tabular}{|c|} 
Age \\
Gender
\end{tabular} & $\begin{array}{c}\text { Automatic (prosaccade) } \\
\text { eye movements }\end{array}$ & $\begin{array}{c}\text { Saccade } \\
\text { task }\end{array}$ & $\begin{array}{c}\text { Excentric } \\
\text { spots }\end{array}$ & SRT & \begin{tabular}{|c|} 
EyeLink 1000 \\
(SR Research) \\
Head-free infrared \\
camera \\
$1000 \mathrm{~Hz}$
\end{tabular} & No SRT deficit in FASD & \begin{tabular}{|c|} 
Limited sample \\
$\begin{array}{c}\text { No information on parental or personal } \\
\text { alcohol consumption }\end{array}$ \\
No distinction between FAS, pFAS and ARND
\end{tabular} & $\begin{array}{c}\text { FASD is associated with preserved } \\
\text { early eye movements (initiating a } \\
\text { saccade), but with delayed primary } \\
\text { visual cortex response (M100 } \\
\text { component) }\end{array}$ \\
\hline $\begin{array}{l}\text { Green et al. } \\
(2007)\end{array}$ & 10 & \begin{tabular}{|c|}
9.8 \\
$(0.4)$
\end{tabular} & $40 \%$ & $\begin{array}{l}\text { No FASD } \\
\text { diagnosis }\end{array}$ & $\begin{array}{l}\text { FAE } \\
\text { FAS } \\
\text { ARND }\end{array}$ & NR & \begin{tabular}{|c|} 
ADHD \\
Anxiety / Depression \\
/ Bipolar disorder \\
Oppositional defiant \\
/ Conduct disorder \\
Neurological \\
disorder \\
\end{tabular} & $12 \mathrm{HC}$ & Age & $\begin{array}{c}\text { Automatic (prosaccade) } \\
\text { and controlled } \\
\text { (antisaccade) eye } \\
\text { movements }\end{array}$ & $\begin{array}{c}\text { Saccade } \\
\text { task }\end{array}$ & $\begin{array}{l}\text { Excentric } \\
\text { red spots }\end{array}$ & \begin{tabular}{|c|} 
SRT \\
Saccadic direction \\
errors \\
Express saccades \\
SRT variation \\
coefficient \\
\end{tabular} & $\begin{array}{c}\text { Electrooculogram } \\
\text { Bitemporal } \\
\text { electrodes with } \\
\text { forehead ground } \\
1000 \mathrm{~Hz}\end{array}$ & $\begin{array}{l}\text { Increased SRT and reduced express } \\
\text { saccades in FASD } \\
\text { Increased direction errors for the } \\
\text { prosaccade task in FASD } \\
\text { Increased intra-subject variability for } \\
\text { the antisaccade task in FASD }\end{array}$ & is $\begin{array}{c}\text { Numerous comorbidities and low control on } \\
\text { medication } \\
\text { Limited sample }\end{array}$ & $\begin{array}{c}\text { FASD is associated with impaired } \\
\text { early eye movementst (initiating a } \\
\text { saccade) and lowered control on these } \\
\text { movements }\end{array}$ \\
\hline $\begin{array}{l}\text { Green et al. } \\
(2009)\end{array}$ & 88 & \begin{tabular}{|l|l|}
10.7 \\
$(0.2)$
\end{tabular} & $49 \%$ & $\begin{array}{l}\text { No FASD } \\
\text { diagnosis }\end{array}$ & $\begin{array}{l}\text { FAS } \\
\text { PFAS } \\
\text { ARND }\end{array}$ & NR & $\begin{array}{c}\text { ADHD } \\
\text { Anxiety / Depression } \\
\text { Sleeping disorders } \\
\text { Oppositional defiant } \\
\text { disorder }\end{array}$ & $91 \mathrm{HC}$ & \begin{tabular}{|c|} 
Age \\
Gender
\end{tabular} & $\begin{array}{c}\text { Automatic (prosaccade) } \\
\text { and controlled } \\
\text { (antisaccade) eye } \\
\text { movements }\end{array}$ & $\begin{array}{c}\text { Saccade } \\
\text { task }\end{array}$ & $\begin{array}{l}\text { Excentric } \\
\text { red spots }\end{array}$ & $\begin{array}{c}\text { SRT } \\
\text { Saccadic direction } \\
\text { errors } \\
\text { SRT variation } \\
\text { coefficient }\end{array}$ & $\begin{array}{c}\text { Eye tracker (ISCAN) } \\
\begin{array}{c}\text { Head-mounted } \\
\text { infrared camera }\end{array} \\
240 \mathrm{~Hz}\end{array}$ & $\begin{array}{l}\text { Increased SRT, intra-subject } \\
\text { variability, and direction errors in } \\
\text { FASD } \\
\text { Stronger deficit for children with } \\
\text { more severe disorder with } \\
\text { (FAS>FASARND) and younger } \\
\text { age }(8-10>11-12>13-15)\end{array}$ & $\begin{array}{l}\text { No information on parental alcohol } \\
\text { consumption } \\
\text { Numerous comorbiditites }\end{array}$ & $\begin{array}{c}\text { FASD is associated with impaired } \\
\text { automatic (initiating a saccade) and } \\
\text { controlled (inhibiting a saccade) eye } \\
\text { movements }\end{array}$ \\
\hline $\begin{array}{l}\text { Green et al. } \\
\text { (2013) }\end{array}$ & 14 & $\begin{array}{c}10 \\
(1.6)\end{array}$ & $57 \%$ & $\begin{array}{l}\text { No FASD } \\
\text { diagnosis }\end{array}$ & FASD & NR & \begin{tabular}{|c|} 
ADHD \\
Anxiety / Depression \\
/ Bipolar disorder \\
Oppositional defiant \\
/ Reactive \\
attachment disorder
\end{tabular} & No & 1 & $\begin{array}{c}\text { Automatic (prosaccade) } \\
\text { and controlled } \\
\text { (antisaccade) eye } \\
\text { movements }\end{array}$ & $\begin{array}{c}\text { Saccade } \\
\text { task }\end{array}$ & $\begin{array}{l}\text { Excentric } \\
\text { red spots }\end{array}$ & \begin{tabular}{|c|} 
SRT \\
$\begin{array}{c}\text { Saccadic direction } \\
\text { errors }\end{array}$
\end{tabular} & $\mid \begin{array}{c}\text { Eye tracker (ISCAN) } \\
\text { Head-mounted } \\
\text { infrared camera } \\
240 \mathrm{~Hz}\end{array}$ & $\begin{array}{l}\text { No group comparison, but SRT and } \\
\text { saccadic direction errors results are } \\
\text { similar to those obtained by Green et } \\
\text { al (2007). }\end{array}$ & \begin{tabular}{|c|c|} 
Limited sample \\
No control group \\
et \\
No distinction between FAS, pFAS and ARND \\
No information on parental consumption
\end{tabular} & $\begin{array}{l}\text { SRT delay is negatively correlated with } \\
\text { white matter integrity in the } \\
\text { cerebellum, but positively correlated } \\
\text { with white matter integrity of the } \\
\text { corpus callosum }\end{array}$ \\
\hline $\begin{array}{c}\text { Hemington \& } \\
\text { Reynolds (2014) }\end{array}$ & 18 & $\begin{array}{l}14.4 \\
(0.6)\end{array}$ & $50 \%$ & $\mid \begin{array}{c}\text { No FASD } \\
\text { diagnosis } \\
\text { Uncorrected } \\
\text { visual deficits }\end{array}$ & $\begin{array}{l}\text { FAS } \\
\text { PFAS } \\
\text { ARND }\end{array}$ & NR & \begin{tabular}{|c|} 
ADHD \\
Anxiety / Depression \\
/ Bipolar disordder I \\
Autism spectrum \\
disorder $/$ \\
Obsessive- \\
Compulsive disorder
\end{tabular} & $19 \mathrm{HC}$ & \begin{tabular}{|c|} 
Age \\
Gender
\end{tabular} & $\begin{array}{c}\text { Automatic (prosaccade) } \\
\text { and memory-guided eye } \\
\text { movements }\end{array}$ & $\begin{array}{c}\text { Memory- } \\
\text { guided } \\
\text { saccade } \\
\text { task with } 1 \\
2-3 \text { stimuli }\end{array}$ & $\begin{array}{l}\text { Excentric } \\
\text { spots }\end{array}$ & $\begin{array}{c}\text { Saccadic } \\
\text { sequence errors } \\
\text { Premature } \\
\text { saccades }\end{array}$ & $\begin{array}{c}\text { EyeLink } 1000 \\
\text { (SR Research) } \\
\text { Head-free infrared } \\
\text { camera } \\
500 \mathrm{~Hz}\end{array}$ & $\begin{array}{l}\text { Increased memory-guided saccadic } \\
\text { sequence errors in FASD, } \\
\text { particularly for high memory load } \\
\text { conditions }\end{array}$ & $\begin{array}{l}\text { Limited sample } \\
\text { No information on parental consumption } \\
\text { Mostly ARND and pFAS participants }\end{array}$ & $\begin{array}{l}\text { FASD is associated with impaired } \\
\text { working memory indexed by } \\
\text { increased error rates for memory- } \\
\text { guided saccadic sequenceses and } \\
\text { reduced alphaltheta band power }\end{array}$ \\
\hline
\end{tabular}




\begin{tabular}{|c|c|c|c|c|c|c|c|c|c|c|c|c|c|c|c|c|c|}
\hline & & & & & & & $\begin{array}{c}\text { Oppositional defiant } \\
/ \text { Attachment } \\
\text { disorder }\end{array}$ & & & & & & & & & & \\
\hline $\begin{array}{l}\text { Paolozzza et al. } \\
\text { (2013) }\end{array}$ & 27 & \begin{tabular}{|l}
12.0 \\
$(1)$
\end{tabular} & $48 \%$ & $\begin{array}{c}\text { No FASD } \\
\text { diagnosis } \\
\text { Less than } \\
50 \% \text { of valid } \\
\text { trials in each } \\
\text { task }\end{array}$ & $\begin{array}{l}\text { FAS } \\
\text { pFAS } \\
\text { ARND }\end{array}$ & NR & $\begin{array}{c}\text { ADHD } \\
\text { Anxiety / Depression } \\
\text { Bipolar disorders } \\
\text { Oppositional defiant } \\
\text { disorder }\end{array}$ & $27 \mathrm{HC}$ & $\begin{array}{l}\text { Age } \\
\text { Gender }\end{array}$ & $\begin{array}{c}\text { Automatic (prosaccade), } \\
\text { controlled (antisaccade) } \\
\text { and memory-based eye } \\
\text { movements }\end{array}$ & $\begin{array}{c}\text { Saccade } \\
\text { task }\end{array}$ & $\begin{array}{l}\text { Excentric } \\
\text { spots }\end{array}$ & \begin{tabular}{|c|} 
SRT \\
Saccade \\
amplitude, velocity, \\
trajectory, \\
correction and \\
endpoint
\end{tabular} & \begin{tabular}{|c|} 
EyeLink 1000 \\
(SR Research) \\
Head-free infrared \\
camera \\
$500 \mathrm{~Hz}$
\end{tabular} & $\begin{array}{l}\text { Higher variability in the saccadic } \\
\text { endpoints and frequency of } \\
\text { corrective sacccades in FASD } \\
\text { Higher error rates and lower } \\
\text { saccadic accuracy in FASD, } \\
\text { particularly for memory/inhibition } \\
\text { processes }\end{array}$ & $\begin{array}{c}\text { No distinction between FAS, pFAS and ARND } \\
\text { Mostly ARND participants } \\
\begin{array}{c}\text { Simultaneous involvement of visuo-motor and } \\
\text { cognitive functions }\end{array}\end{array}$ & $\begin{array}{l}\text { FASD is associated with higher } \\
\text { variability and lower accuracy in } \\
\text { saccadic eye movements, particularly } \\
\text { in tasks requesting cognitive abilitities }\end{array}$ \\
\hline $\begin{array}{l}\text { Paolozza et al. } \\
\text { (2014a) }\end{array}$ & 69 & \begin{tabular}{|l}
11.6 \\
$(3)$
\end{tabular} & $55 \%$ & $\begin{array}{c}\text { No FASD } \\
\text { diagnosis } \\
\text { Less than } \\
50 \% \text { of valid } \\
\text { trials in each } \\
\text { task }\end{array}$ & $\begin{array}{l}\text { FAS } \\
\text { pFAS } \\
\text { ARND }\end{array}$ & $\mathrm{NR}$ & $\begin{array}{c}\text { ADHD } \\
\text { Anxiety / Depression } \\
\text { Bipolar disorders } \\
\text { Oppositional defiant } \\
\text { disorder }\end{array}$ & \begin{tabular}{|c|}
$111 \mathrm{HC}$ \\
13 children \\
with PAE
\end{tabular} & $\begin{array}{l}\text { Age } \\
\text { Gender }\end{array}$ & $\begin{array}{c}\text { Automatic (prosaccade), } \\
\text { controlled (antisaccade) } \\
\text { and memory-based eye } \\
\text { movements }\end{array}$ & $\begin{array}{c}\text { Saccade } \\
\text { task }\end{array}$ & $\begin{array}{l}\text { Excentric } \\
\text { spots }\end{array}$ & $\begin{array}{c}\text { Saccadic endpoint } \\
\text { and sequence }\end{array}$ & \begin{tabular}{|c|} 
Eyelink 1000 \\
(SR Research) \\
Head-free infrared \\
camera \\
$500 \mathrm{~Hz}$
\end{tabular} & \begin{tabular}{|c|} 
Increased saccadic error rates in \\
prosaccade, antisaccade and \\
memory-based tasks in FASD \\
Correlation between prosaccade \\
endpoint errors and visuospatial \\
performance in FASD \\
Correlation between memory-based \\
sequence errors and working \\
memory in FASD
\end{tabular} & $\begin{array}{l}\text { Numerous comorbidities } \\
\text { Mostly ARND participants } \\
\text { Correlational analysis only } \\
\text { Uncorrected multiple comparisons }\end{array}$ & $\begin{array}{l}\text { FASD is associated with higher } \\
\text { saccadic errors and } \\
\text { visuospatial/ working memory } \\
\text { impairmentst, these deficitits being } \\
\text { correlated }\end{array}$ \\
\hline $\begin{array}{l}\text { Paolozzza et al. } \\
\text { (2014b) }\end{array}$ & 66 & $\begin{array}{l}11.5 \\
(3)\end{array}$ & $53 \%$ & $\begin{array}{c}\text { No FASD } \\
\text { diagnosis } \\
\text { Less than } \\
50 \% \text { of valid } \\
\text { trials in each } \\
\text { task }\end{array}$ & $\begin{array}{l}\text { FAS } \\
\text { pFAS } \\
\text { ARND }\end{array}$ & NR & $\begin{array}{c}\text { ADHD } \\
\text { Anxiety / Depression } \\
\text { Bipolar disorders } \\
\text { Oppositional defiant } \\
\text { disorder }\end{array}$ & \begin{tabular}{|c|}
$105 \mathrm{HC}$ \\
14 children \\
with PAE
\end{tabular} & $\begin{array}{l}\text { Age } \\
\text { Gender }\end{array}$ & $\begin{array}{c}\text { Controlled (antisaccade) } \\
\text { and memory-based eye } \\
\text { movements }\end{array}$ & $\begin{array}{c}\text { Saccade } \\
\text { task }\end{array}$ & $\begin{array}{l}\text { Excentric } \\
\text { spots }\end{array}$ & Saccade direction & \begin{tabular}{|c|} 
EyeLink 1000 \\
(SR Research) \\
Head-free infrared \\
camera \\
$500 \mathrm{~Hz}$ \\
\end{tabular} & $\begin{array}{l}\text { Increased saccadic error rates in } \\
\text { antisaccade and memory-based } \\
\text { tasks in FASD } \\
\text { Correlation between antisaccade } \\
\text { and executive deficits (switching, } \\
\text { inhibitition) in FASD }\end{array}$ & $\begin{array}{l}\text { Numerous comorbidities } \\
\text { Mostly ARND participants } \\
\text { No eye tracking measures reported } \\
\text { Correlational analysis only }\end{array}$ & $\begin{array}{l}\text { FASD is associated with higher } \\
\text { saccadic errors and executive } \\
\text { impairments, these deficits being } \\
\text { correlated }\end{array}$ \\
\hline $\begin{array}{l}\text { Paolozzza et al. } \\
\text { (2014c) }\end{array}$ & 43 & \begin{tabular}{|l|}
12.3 \\
$(3.1)$
\end{tabular} & $53 \%$ & $\begin{array}{c}\text { No FASD } \\
\text { diagnosis } \\
\text { Less than } \\
50 \% \text { of valid } \\
\text { trials in each } \\
\text { task }\end{array}$ & $\begin{array}{r}\text { FAS } \\
\text { pFAS } \\
\text { ARND }\end{array}$ & $N R$ & $\begin{array}{c}\text { ADHD } \\
\text { Anxiety / Depression } \\
\begin{array}{c}\text { Oppositional defiant } \\
\text { disorder }\end{array}\end{array}$ & $35 \mathrm{HC}$ & $\begin{array}{l}\text { Age } \\
\text { Gender }\end{array}$ & $\begin{array}{c}\text { Controlled (antisaccade) } \\
\text { and memory-based eye } \\
\text { movements }\end{array}$ & $\begin{array}{c}\text { Saccade } \\
\text { task }\end{array}$ & $\begin{array}{l}\text { Excentric } \\
\text { spots }\end{array}$ & \begin{tabular}{|c|} 
SRT \\
Anticipatory/directi \\
on errors \\
(antisaccade) \\
Sequence/timing \\
errors (memory- \\
guided) \\
\end{tabular} & \begin{tabular}{|c|} 
EyeLink 1000 \\
(SR Research) \\
Head-free infrared \\
camera \\
$500 \mathrm{~Hz}$
\end{tabular} & $\begin{array}{c}\text { Slower SRT and higher } \\
\text { anticipatory/direction error rates in } \\
\text { the antisaccade task in FASD } \\
\text { Higher sequence/timing error rates in } \\
\text { the memory-guided task in FASD }\end{array}$ & $\begin{array}{c}\text { Numerous comorbidities } \\
\text { Mostly ARND participants } \\
\text { Correlational analyses only } \\
\text { Brain exploration focused on corpus callosum }\end{array}$ & $\begin{array}{l}\text { FASD is associated with slower } \\
\text { saccades and higher saccadic errors, } \\
\text { which is related to toplenium } \\
\text { abnormalities }\end{array}$ \\
\hline $\begin{array}{l}\text { Paolozzza et al. } \\
\text { (2015) }\end{array}$ & 71 & \begin{tabular}{|l}
11.8 \\
$(0.4)$
\end{tabular} & $55 \%$ & $\begin{array}{c}\text { No FASD } \\
\text { diagnosis } \\
\text { Less than } \\
50 \% \text { of valid } \\
\text { trials in each } \\
\text { task }\end{array}$ & $\begin{array}{l}\text { FAS } \\
\text { pFAS } \\
\text { ARND }\end{array}$ & $N R$ & $\begin{array}{c}\text { ADHD } \\
\text { Anxiety / Depression } \\
\text { Oppositional defiant } \\
\text { disorder }\end{array}$ & $113 \mathrm{HC}$ & $\begin{array}{l}\text { Age } \\
\text { Gender }\end{array}$ & $\begin{array}{c}\text { Automatic (prosaccade) } \\
\text { eye movements }\end{array}$ & $\begin{array}{c}\text { Saccade } \\
\text { task }\end{array}$ & $\begin{array}{l}\text { Excentric } \\
\text { spots }\end{array}$ & \begin{tabular}{c|} 
SRT \\
Saccadic \\
amplitude \\
Saccade endpoint
\end{tabular} & \begin{tabular}{|c|} 
Eyelink 1000 \\
(SR Research) \\
Head-free infrared \\
camera \\
$500 \mathrm{~Hz}$
\end{tabular} & $\begin{array}{l}\text { Reduced saccade accuracy/speed in } \\
\text { FASD } \\
\text { Higher variability in saccadic } \\
\text { endpoints and slower saccades in } \\
\text { FASD males } \\
\text { Reduced saccadic amplitude in } \\
\text { FASD females }\end{array}$ & $\begin{array}{l}\text { Numerous comorbidities } \\
\text { Mostly ARND participants } \\
\text { No information on parental alcohol } \\
\text { consumption }\end{array}$ & $\begin{array}{l}\text { FASD is related to gender-specific } \\
\text { differences in eye movements } \\
\text { impairments (reduced speed//recision } \\
\text { in males, reduced amplitude in } \\
\text { females) }\end{array}$ \\
\hline $\begin{array}{l}\text { Paolozzza et al. } \\
\text { (2016) }\end{array}$ & 66 & \begin{tabular}{|l|}
11.8 \\
$(3.4)$
\end{tabular} & $53 \%$ & $\begin{array}{l}\text { No FASD } \\
\text { diagnosis }\end{array}$ & $\begin{array}{l}\text { FAS } \\
\text { pFAS } \\
\text { ARND }\end{array}$ & $\mathrm{NR}$ & $\begin{array}{c}\text { ADHD } \\
\text { Anxiety / Depression }\end{array}$ & $102 \mathrm{HC}$ & $\begin{array}{l}\text { Age } \\
\text { Gender }\end{array}$ & $\begin{array}{c}\text { Automatic (prosaccade) } \\
\text { eye movements }\end{array}$ & $\begin{array}{c}\text { Saccade } \\
\text { task }\end{array}$ & $\begin{array}{l}\text { Excentric } \\
\text { spots }\end{array}$ & $\begin{array}{c}\text { SRT } \\
\text { Saccadic } \\
\text { amplitude }\end{array}$ & $\begin{array}{l}\text { EyeLink } 1000 \\
\text { (SR Research) }\end{array}$ & $\begin{array}{c}\text { Faster saccadic reaction time and } \\
\text { reduced saccade amplitude when } \\
\text { the target appears at the opposite } \\
\text { side than in previous trial }\end{array}$ & $\begin{array}{l}\text { Numerous comorbidities } \\
\text { Mostly ARND participants }\end{array}$ & $\begin{array}{l}\text { FASD is related to preserved } \\
\text { immediate neural plasticity in the } \\
\text { visual system }\end{array}$ \\
\hline
\end{tabular}




\begin{tabular}{|c|c|c|c|c|c|c|c|c|c|c|c|c|c|c|c|c|c|}
\hline & & & & $\begin{array}{l}\begin{array}{l}\text { Less than } \\
50 \% \text { of valid } \\
\text { trials in each } \\
\text { task }\end{array} \\
\end{array}$ & & & $\begin{array}{c}\text { Oppositional defiant } \\
\text { disorder }\end{array}$ & & $\left|\begin{array}{l}(\text { no strict } \\
\text { matching) }\end{array}\right|$ & & & & & $\begin{array}{c}\text { Head-free infrared } \\
\text { camera } \\
500 \mathrm{~Hz} \\
\end{array}$ & & $\begin{array}{l}\text { No information on parental alcohol } \\
\text { consumption }\end{array}$ & \\
\hline $\begin{array}{l}\text { Paolozza et al. } \\
\text { (2017) }\end{array}$ & 69 & \begin{tabular}{|l}
12.5 \\
$(3.2)$
\end{tabular} & $48 \%$ & $\begin{array}{l}\text { Less than } \\
50 \% \text { of valid } \\
\text { trialin each } \\
\text { task }\end{array}$ & $\begin{array}{c}\text { FAS } \\
\text { pFAS } \\
\text { ARND } \\
\text { PAE }\end{array}$ & NR & \begin{tabular}{|c|} 
ADHD \\
$\begin{array}{c}\text { Anxiety / Depression } \\
\text { Oppositional defiant } \\
\text { disorder }\end{array}$ \\
\end{tabular} & $67 \mathrm{HC}$ & $\begin{array}{c}\text { Age } \\
\text { Gender }\end{array}$ & $\begin{array}{c}\text { Automatic (prosaccade) } \\
\text { eye movements }\end{array}$ & $\begin{array}{c}\text { Saccade } \\
\text { task }\end{array}$ & $\begin{array}{l}\text { Excentric } \\
\text { spots }\end{array}$ & $\begin{array}{c}\text { SRT } \\
\text { Anticipatory } \\
\text { saccades } \\
\text { Saccade endpoint } \\
\end{array}$ & $\begin{array}{c}\text { Eyelink 1000 } \\
\text { (SR Research) } \\
\text { Head-free infrared } \\
\text { camera } \\
500 \mathrm{~Hz} \\
\end{array}$ & $\mid \begin{array}{c}\text { No eye tracking results reported } \\
\text { (only correlations with neuroimaging } \\
\text { results) }\end{array}$ & $\begin{array}{l}\text { Numerous comorbidities } \\
\text { Mixing between FASD and PAE } \\
\text { No eye tracking results reported }\end{array}$ & $\begin{array}{c}\text { FASD and PAE are related to impaired } \\
\text { white matter integrity, which is not } \\
\text { correlated with eye movements } \\
\text { impairments }\end{array}$ \\
\hline $\begin{array}{l}\text { Stephen et al. } \\
\text { (2013) }\end{array}$ & 15 & \begin{tabular}{|l}
15.3 \\
$(2.1)$
\end{tabular} & $67 \%$ & $\begin{array}{l}\text { No FASD } \\
\text { diagnosis }\end{array}$ & $\begin{array}{r}\text { FAS } \\
\text { ARND }\end{array}$ & $N R$ & $N R$ & $20 \mathrm{HC}$ & $\begin{array}{c}\text { Age } \\
\text { Gender }\end{array}$ & $\begin{array}{c}\text { Automatic (prosaccade) } \\
\text { eye movements }\end{array}$ & $\begin{array}{c}\text { Saccade } \\
\text { task }\end{array}$ & $\begin{array}{c}\text { Excentric } \\
\text { spots }\end{array}$ & $\begin{array}{c}\text { SRT } \\
\text { Saccadic } \\
\text { amplitude } \\
\text { Saccadic peak } \\
\text { velocity }\end{array}$ & \begin{tabular}{|c|} 
Eyelink 1000 \\
(SR Research) \\
Head-free infrared \\
camera \\
$1000 \mathrm{~Hz}$
\end{tabular} & $\begin{array}{l}\text { No SRT, saccadic amplitude and } \\
\text { saccadic peak velocity deficits in } \\
\text { FASD }\end{array}$ & $\begin{array}{l}\text { Limited sample } \\
\begin{array}{l}\text { No information on parental or personal } \\
\text { alcohol consumption }\end{array} \\
\text { Limited use of eye tracking measures }\end{array}$ & $\begin{array}{c}\text { FASD is associated with preserved } \\
\text { early eye movements (saccade } \\
\text { initiation, amplitude and velocity, but } \\
\text { with modified gamma-band activity in } \\
\text { the cerebral saccade network }\end{array}$ \\
\hline $\begin{array}{l}\text { Tseng et al. } \\
\text { (2013) }\end{array}$ & 13 & \begin{tabular}{|l|}
12.3 \\
$(2.1)$
\end{tabular} & $54 \%$ & $\begin{array}{c}\text { No FASD } \\
\text { diagnosis } \\
\text { Visual } \\
\text { impairments }\end{array}$ & $\begin{array}{l}\text { FAS } \\
\text { pFAS } \\
\text { ARND }\end{array}$ & $N R$ & $\begin{array}{c}\text { ADHD } \\
\text { Anxiety / Depression } \\
\text { Bipolar disorder }\end{array}$ & $24 \mathrm{HC}$ & NR & $\begin{array}{l}\text { Oculomotor, saliency } \\
\text { and group features } \\
\text { related to eye } \\
\text { movements }\end{array}$ & \begin{tabular}{|l|} 
Free visual \\
exploration
\end{tabular} & $\begin{array}{l}\text { TV and } \\
\text { videogames } \\
\text { excerpts }\end{array}$ & $\begin{array}{l}\text { Saccades } \\
\text { Dwell time } \\
\text { Gaze pattern }\end{array}$ & $\begin{array}{c}\text { EyeLink II } \\
\text { (SR Research) } \\
\text { Head-mounted } \\
\text { infrared camera } \\
500 \mathrm{~Hz} \\
\end{array}$ & $\begin{array}{l}\text { Atypical top-down/bottom-up } \\
\text { attention control in } \mathrm{FASD} \\
\text { Efficient classification of FASD, } \\
\text { compared with HC or ADHD }\end{array}$ & \begin{tabular}{|c|} 
Limited sample \\
No distinction between FAS, pFAS and ARND \\
No control of medication \\
Limited efficiency of the categorization tool \\
\end{tabular} & $\begin{array}{c}\text { FASD can be identified through a } \\
\text { machine learning-based classifier } \\
\text { based on eye-movements recording }\end{array}$ \\
\hline $\begin{array}{l}\text { Zhang et al. } \\
\text { (2019) }\end{array}$ & \begin{tabular}{|c}
71 \\
(Proscaccede \\
task) \\
67 \\
(Antisaccade \\
task) \\
61 \\
(Memory- \\
guided task)
\end{tabular} & \begin{tabular}{|l|}
11.9 \\
$(3.4)$
\end{tabular} & $46 \%$ & $\begin{array}{l}\text { No FASD } \\
\text { diagnosis }\end{array}$ & $\begin{array}{l}\text { FAS } \\
\text { pFAS } \\
\text { ARND }\end{array}$ & $N R$ & NR & $\begin{array}{l}71 \mathrm{HC} \\
\text { (Prosaccad } \\
\text { e task) } \\
67 \mathrm{HC} \\
\text { (Antisaccad } \\
\text { e task) } \\
61 \mathrm{HC} \\
\text { (Memory- } \\
\text { guided task) }\end{array}$ & Age range & $\begin{array}{c}\text { Automatic (prosaccade), } \\
\text { controlled (antisaccade) } \\
\text { and memory-based eye } \\
\text { movements }\end{array}$ & $\begin{array}{c}\text { Saccade } \\
\text { task } \\
\text { Free visual } \\
\text { exploration }\end{array}$ & $\begin{array}{l}\text { Excentric } \\
\text { spots } \\
\text { Videoclips }\end{array}$ & $\begin{array}{l}18 \text { (prosaccade } \\
\text { task), 15 } \\
\text { (antisaccade task) } \\
\text { and } 26 \text { (memory- } \\
\text { guided task) eye } \\
\text { movements } \\
\text { indexes (e.g., SRT, } \\
\text { saccade velocity, } \\
\text { amplitude, } \\
\text { acceleration) }\end{array}$ & $\begin{array}{c}\text { Eyelink } 1000 \\
\text { (SR Research) } \\
\text { Head-free infrared } \\
\text { camera } \\
500 \mathrm{~Hz}\end{array}$ & 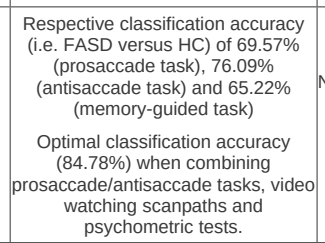 & \begin{tabular}{|c|c|} 
No distinction between FAS, pFAS and ARND \\
No control of comorbidities \\
No information on parental or personal \\
alcohol consumption
\end{tabular} & $\begin{array}{l}\text { FASD can be identified with a high } \\
\text { accuracy by using a two-step } \\
\text { screening protocol based on (1) } \\
\text { prosaccade task/video watching } \\
\text { scanpaths; (2) antisaccade task } \\
\text { and/or neuropsychological tests } \\
\text { (particularly for older individuals) }\end{array}$ \\
\hline
\end{tabular}

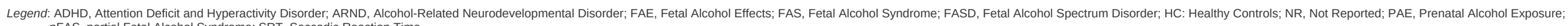
pFAS, partial Fetal Alcohol Syndrome; SRT, Saccadic Reaction Time 